\title{
Development of innovative hybrid sandwich panel slabs:
}

\section{Advanced numerical simulations and parametric studies}

\section{Mastali ${ }^{1 *}$, I. B. Valente ${ }^{2}$, Joaquim A. O. Barros ${ }^{3}$}

1. ISISE, Dep. Civil Eng., School Eng., University of Minho Campus de Azurém 4800058 Guimarães, Portugal. Corresponding author Email*: m.mastali@civil.uminho.pt Telephone*: 00351-915427040

2. Assistant Professor, Minho University, Department of Civil Engineering, Campus de Azurém, 4800-058 Guimarães, Portugal. Email: isabelv@civil.uminho.pt 3. Full Professor, Minho University, Department of Civil Engineering, Campus de Azurém, 4800-058 Guimarães, Portugal. Email: barros@civil.uminho.pt

\begin{abstract}
An innovative hybrid sandwich slab for the rehabilitation of floors in old masonry buildings was conceived, designed, and tested. This structural system is a lightweight composite floor consisting of bottom skin and shear ribs in Glass Fiber Reinforced Polymer (GFRP), a top layer of Deflection Hardening Cement Composites (DHCC), and Polyurethane foam core. In the first part of this study, the material/structural performance of the panel's concept was assessed by experimental tests. The second part is now dedicated to the execution of advanced numerical simulations, including parametric studies, for assisting on the optimization of this composite slab system and investigating the influence of the relevant characteristics of GFRP and DHCC components. The influence of considering isotropic or orthotropic behavior for the GFRP components and linear or nonlinear behavior for the DHCC are also investigated numerically in terms of accomplishing serviceability and ultimate limit state requisites for this structural system. The parametric studies show that the parametric studies.

Paper submitted to Composite Structures, Elsevier, ISSN 0263-8223.
\end{abstract}


thickness of GFRP rib is the most important parameter to increase the load carrying capacity of this type of slabs. Based on the results of these parametric studies, two slabs are built and tested experimentally, and the obtained results are not only used to demonstrate the effectiveness of the developed structural system, but also to appraise the predictive performance of the constitutive models adopted in the FEM-based simulations.

Keywords: Composite slabs, Rehabilitation, GFRP, Fiber reinforced cement composites, FEM analysis

Mastali, Mohammad, Valente, Isabel B., Barros, Joaquim A. O. (2016).

Development of innovative hybrid sandwich panel slabs: Advanced numerical simulations and parametric studies.

Paper submitted to Composite Structures, Elsevier, ISSN 0263-8223. 


\section{Introduction}

Sandwich panels are lightweight construction systems of high strength-to-weight ratio. A typical sandwich panel consists of a low-density core material with two thin outer faces. The skins have a relatively high stiffness and high tensile strength, assuring the panel's flexural capacity, while the low-density core material provides appropriate thermal insulating properties and might offer some shear resistance. The structural behavior of a sandwich panel strongly depends on the geometry, arrangement and properties of its components. Numerous experimental and numerical studies have been developed during the last decade for assessing and enhancing the structural behavior of sandwich panel systems.

Ziad et al. [1] worked on the experimental and numerical analysis of an innovative Glass Fiber Reinforced Polymer (GFRP) sandwich floor panel subjected to a concentrated load. The proposed sandwich panel was developed to be used as a slab system, comprising a modified phenolic core in-between top and bottom skins made by bi-axial E-CR glass fibers at $0^{\circ} / 90^{\circ}$ orientation angles. This study presented the results of the experimental behavior and the nonlinear finite element analysis of the GFRP sandwich panel. The behavior of the GFRP sandwich panel, skin-core interaction, and core of GFRP sandwich panel were investigated experimentally [1]. From the obtained results, it was verified that the failure of the modified phenolic core occurred without detachment of the skin-core interface, which means that the skin-core interaction did not have significant effect on the failure behavior. The modified phenolic cores failed due to shear effects. Moreover, material nonlinear analysis using Finite Element Method (FEM) was carried out to simulate the experimental test on a GFRP sandwich panel slab. A linear behavior for the GFRP with a stress field limit governed by the Hashin failure criterion was considered, while for the phenolic core, the crushable foam model available in ABAQUS was used [1].

In 2015, Raj et al. [2] developed a basalt fiber reinforced composite (BFRC) sandwich panel consisting of a prefabricated corrugated plate with basalt fibers reinforced polymer (BFRP) working like a permanent mold in the bottom face of a cast in place concrete slab, and

Mastali, Mohammad, Valente, Isabel B., Barros, Joaquim A. O. (2016).

Development of innovative hybrid sandwich panel slabs: Advanced numerical simulations and parametric studies.

Paper submitted to Composite Structures, Elsevier, ISSN 0263-8223. 
providing to this system the required tensile capacity. The panel was tested experimentally under four point bending load conditions. The deflection at peak load was almost 1.7 times higher than the deflection at service limit state $(L / 250=6 \mathrm{~mm}$, where $L=1500 \mathrm{~mm}$ is the slab's span length), and after peak load a smooth structural softening stage was observed with a decrease in load capacity of less than $10 \%$, up to a deflection that is two times higher than the deflection at peak load. This behaviourrevealed a certain ductile behavior for this construction system. This system failed by a combination of delamination between the two constituent materials and concrete crushing. By using ABAQUS software with a concrete damage plasticity (CDP) model to simulate the nonlinear behavior of concrete, cohesivezone model for the concrete-BFRP plate interface, and assuming linear-elastic behavior for the BRFP, a deviation of about $4 \%$ on the maximum load of the experimentally tested slab was obtained. Moreover, the numerical simulations have indicated that by assuring anchorage mechanism that avoid premature concrete-BFRP debonding, the stiffness and the maximum load carrying capacity of this slab system are increased [2].

Mostafa et al. [3] presented a sandwich panel designed toward an improved behavior in terms of shear performance, by using shear keys with semi-circular shape. The shear keys, of chopped strand (CS) glass fibers impregnated by epoxy resin, were installed between the GFRP skins and foam (Polyvinylchloride, PVC, and polyurethane, PU, were investigated) in an attempt of increasing the in-plane shear resistance of this interface zone [3]. By using ABAQUS computer program, assuming linear elastic behavior for all the intervening materials, and adopting contact elements for modeling the interface between shear keys and surrounding materials, a parametric study was executed for assessing the influence of the diameter and spacing of these shear keys on the in-plane shear performance of this type of sandwich panel, and an optimized configuration was determined [3].

By considering the nonlinear behavior of the materials and the geometric nonlinear response of the structural system, through a 3D FEM model, Sharaf and Fam [4] analyzed large-scale sandwich panels with internal ribs, tested under transverse loading. These simulations were parametric studies.

Paper submitted to Composite Structures, Elsevier, ISSN 0263-8223. 
capable of capturing the global structural behavior and the local failure modes registered experimentally, which were essentially skin wrinkling and crushing in compression. In 2015, Mastali et al. [5] proposed an innovative hybrid sandwich panel formed by a GFRP bottom tension, a Deflection Hardening Cement Composite (DHCC) top compression layer, GFRP shear ribs and foam core material. The DHCC layer has the purpose of increasing the stiffness, ductility, impact resistance and acoustic performance of the panel. In addition, it constitutes a proper substrate for the application of floor cover materials and provides extra fire protection to the panel (see Fig. 1a).

Fig 1.

An extensive experimental program was executed at Minho University to investigate the flexural performance of this hybrid slab system [5]. For all experimental tests, a constant distance of $400 \mathrm{~mm}$ between GFRP ribs was considered. As presented in [5], this distance guarantees an adequate flexural performance of the DHCC layer. Following the experimental program presented in [5], it was decided to perform a parametric study on one-way bending slabs to assess the influence of the geometric and material properties of the constituents of this slab system in its global behavior.

Therefore, the first part of the present paper is dedicated to these parametric studies, carried out in two different phases: $\left.1^{\text {st }}\right)$ FEM analyses were executed assuming a linear orthotropic behavior for GFRP skin and ribs, while a linear-elastic-isotropic behavior was considered for the DHCC layer; $2^{\text {nd }}$ ) an elasto-crack constitutive model was adopted to simulate the nonlinear behavior of DHCC layer due to crack initiation and propagation, while GFRP ribs and skin were assumed to have a linear orthotropic behavior.

The second part of this paper is mainly devoted to 3D FEM simulations of the hybrid slabs, with special focus on modeling the interfaces between slab's components. The bilinear Cohesive Zone Model (CZM) is used to simulate the interface between slab's components. The CZM parameters are unknown, as they depend on the bond interaction between three materials (GFPR rib, foam core, and DHCC material).

Mastali, Mohammad, Valente, Isabel B., Barros, Joaquim A. O. (2016).

Development of innovative hybrid sandwich panel slabs: Advanced numerical simulations and parametric studies.

Paper submitted to Composite Structures, Elsevier, ISSN 0263-8223. 
Thus, an inverse analysis procedure is executed with ABAQUS software in order to obtain the unknown parameters of the bilinear cohesive zone model. This analysis was carried out to best-fit the experimental results in terms of force-deflection and force-strain relationships, and to well capture of the observed damages.

\section{FEM model approaches}

The constitutive models adopted in FEMIX and ABAQUS computer programs for modeling the behavior of the hybrid slab constituent materials are briefly presented in this section.

\subsection{Introduction}

FEMIX 4.0 is a computer code whose purpose is the analysis of structures by the Finite Element Method (FEM) $[10,28]$. This code is based on the displacement method, and offers a large library of finite element types, namely 3D frames and trusses, plane stress elements, flat or curved elements for shells, and 3D solid elements. Linear elements may have two or three nodes, plane stress and shell elements may be 4,8 or 9 -noded and 8 or 20 noded hexahedra may be used in 3D solid analyses. This element library is complemented with a set of point, line and surface springs that model elastic contact with the supports, and also several types of interface elements to model inter-element contact. Embedded line elements can be added to other types of elements to model reinforcement bars. All these types of elements can be simultaneously included in the same analysis, with the exception of some incompatible combinations. The analysis may be static or dynamic and the material behavior may be linear or nonlinear. Data input is facilitated by the possibility of importing CAD models. Post processing is performed with a general-purpose scientific visualization program named draw mesh, or more recently by associating FEMIX 4.0 with GID software [29].

Advanced numerical techniques are available, like the Newton-Raphson method combined with path dependent or independent algorithms and arc-length techniques. When the size of

Mastali, Mohammad, Valente, Isabel B., Barros, Joaquim A. O. (2016).

Development of innovative hybrid sandwich panel slabs: Advanced numerical simulations and parametric studies.

Paper submitted to Composite Structures, Elsevier, ISSN 0263-8223. 
the systems of linear equations is very large, a preconditioned conjugate gradient method can be advantageously used.

ABAQUS is a commercial software with several FEM-based potentialities for a multi-physics modeling in structural analysis [6].

\subsection{Constitutive models adopted in FEMIX simulations}

The Reissner-Mindlin shell theory was selected to simulate the behavior of the slab system. GFRP materials were modeled assuming linear-elastic behavior, with two alternatives: isotropic and orthotropic. Since experimental tests have demonstrated that foam cores had no significant contribution for the load carrying capacity and flexural performance of the hybrid slabs, this material was not considered in the simulations with FEMIX. The DHCC is the material of the slab system more prone to develop nonlinear behavior due to cracking. Therefore, the influence of considering the linear or the nonlinear behavior of DHCC on the performance of the slab system was investigated in the parametric studies. The damage due to crack formation and propagation was simulated by discretizing the thickness of the DHCC in ten layers. Fibers bridging micro-cracks contribute to the formation of diffuse crack patterns, since they offer resistance to the coalescence of the earlier micro-cracks into macro-cracks. Therefore, smeared crack constitutive models are, conceptually, more appropriate than discrete crack models in the simulation of crack propagation in fiber reinforced cement composites (FRCC) structures, mainly, in those with a high number of redundant supports, such as the present case (the DHCC layer is supported on the GFRP ribs) [7]. In the present section only the relevant aspects of the adopted multidirectional fixed smeared crack model available in FEMIX 4.0 software are pointed out, since its full description can be found elsewhere [7]. For the case of cracked concrete, the constitutive law is defined by Eq. (1),

Mastali, Mohammad, Valente, Isabel B., Barros, Joaquim A. O. (2016).

Development of innovative hybrid sandwich panel slabs: Advanced numerical simulations and parametric studies.

Paper submitted to Composite Structures, Elsevier, ISSN 0263-8223. 


$$
\left[\begin{array}{c}
\Delta \underline{\sigma}_{m f} \\
\underline{\sigma}_{s}
\end{array}\right]=\left[\begin{array}{cc}
\underline{D}_{m f}^{c r c o} & \underline{0} \\
\underline{0} & \underline{D}_{s}^{c r c o}
\end{array}\right]\left[\begin{array}{c}
\Delta \underline{\varepsilon}_{m f} \\
\underline{\boldsymbol{\varepsilon}}_{s}
\end{array}\right]
$$

where $\Delta \underline{\sigma}_{m f}$ and $\Delta \underline{\varepsilon}_{m f}$ are the vectors corresponding to the in-plane stress and strain increment components, respectively (membrane and bending components); $\underline{\sigma}_{s}$ and $\underline{\varepsilon}_{s}$ are the vectors corresponding to the out-of-plane shear stress and shear strain components, respectively, and $\underline{D}_{m f}^{c r c o}$ is the in-plane cracked concrete constitutive matrix [8].

Fig. 2 defines the fracture mode I modulus, $D_{I}^{c r}$, where $\alpha_{i}$ and $\xi_{i}$ are the parameters that define the shape of the crack's normal stress vs. normal strain diagram. The ultimate crack normal strain $\left(\varepsilon_{n, u}^{c r}\right)$ is defined as a function of $\alpha_{i}$ and $\xi_{i}$ parameters, fracture energy $\left(G_{f}^{I}\right)$, tensile strength $\left(f_{c t}=\sigma_{n, l}^{c r}\right)$ and crack bandwidth $\left(l_{b}\right)[7]$.

Fig 2.

$$
\begin{gathered}
\sigma_{n, 1}^{c r}=f_{c t}, \sigma_{n, 2}^{c r}=\alpha_{1} \sigma_{n, 1}^{c r}, \sigma_{n, 3}^{c r}=\alpha_{2} \sigma_{n, 1}^{c r}, \varepsilon_{n, 2}^{c r}=\xi_{1} \varepsilon_{n, u}^{c r}, \varepsilon_{n, 3}^{c r}=\xi_{2} \varepsilon_{n, u}^{c r} \\
D_{I, i}^{c r}=-k_{i} \frac{l_{c r} f^{2}{ }_{c t}}{G_{f}} \\
k_{1}=\frac{\left(1-\alpha_{1}\right)\left(\xi_{1}+\alpha_{1} \xi_{2}-\alpha_{2} \xi_{1}+\alpha_{2}\right)}{2 \xi_{1}} \\
k_{2}=\frac{\left(\alpha_{1}-\alpha_{2}\right)\left(\xi_{1}+\alpha_{1} \xi_{2}-\alpha_{2} \xi_{1}+\alpha_{2}\right)}{2\left(\xi_{2}-\xi_{1}\right)} \\
k_{3}=\frac{\alpha_{2}\left(\xi_{1}+\alpha_{1} \xi_{2}-\alpha_{2} \xi_{1}+\alpha_{2}\right)}{2\left(1-\xi_{1}\right)}
\end{gathered}
$$

Regarding fracture mode II, the total and the incremental approaches, schematically represented in Fig. 3 and described in detailed elsewhere [9], are available in FEMIX, but in the simulations carried out the total approach was adopted due to its better performance. As shown in Fig. 3, and demonstrated in Barros et al. 2011 [9], the total approach is capable of

Mastali, Mohammad, Valente, Isabel B., Barros, Joaquim A. O. (2016).

Development of innovative hybrid sandwich panel slabs: Advanced numerical simulations and parametric studies.

Paper submitted to Composite Structures, Elsevier, ISSN 0263-8223. 
simulating the degradation of the crack shear stress transfer above a certain level of crack shear strain, while in the incremental approach, in spite of capturing the crack shear stiffness degradation with the cracking process, the crack shear stress increases with the crack shear strain, regardless the level of crack opening, which does not reproduce correctly the cracking process, leading to deficient predictions, mainly in elements failing in shear. Both approaches mobilize the concept of shear retention factor, $\beta[9,10]$. The shear retention factor is defined in Eq. (7),

$$
\beta=\left(1-\frac{\varepsilon_{n}^{c r}}{\varepsilon_{n, u}^{c r}}\right)^{p_{1}}
$$

where, $p_{1}$ is a parameter to define the decrease rate of $\beta$ with the increase of the crack normal strain component, $\varepsilon_{n}^{c r}$. The values of the model parameters for simulating the behaviour of DHCC are listed in Table 1.

Fig 3.

Table 1.

\subsection{Constitutive models adopted in ABAQUS simulations}

A plastic damage model was used to simulate the DHCC, while foam core was simulated by a crushable foam model. Additionally, GFRP materials were assumed as having orthotropic behavior.

\subsubsection{DHCC}

The concrete damage plasticity (CDP) model was used to simulate the damage due to crack initiation and propagation, as well as the inelastic deformation of cement-based materials in compression. The typical stress-strain response obtained in uniaxial tensile tests is schematically represented in Fig. 4a and Fig. 4b. After a linear response up to the crack initiation, a tensile strain hardening stage, of relative small amplitude, occurs due to the formation of several micro-cracks. This cracking phase is followed by a softening stage up to Mastali, Mohammad, Valente, Isabel B., Barros, Joaquim A. O. (2016).

Development of innovative hybrid sandwich panel slabs: Advanced numerical simulations and parametric studies.

Paper submitted to Composite Structures, Elsevier, ISSN 0263-8223. 
a relatively high tensile strain in consequence of the widening localization in the tensile failure crack. The values adopted for the model parameters are included in Table 1.

Fig 4.

\subsubsection{Foam core}

The crushable model for simulating foam type materials was used, by considering null tensile capacity and a compressive stress-strain response represented by the diagram depicted in Fig. 4c. The values adopted for the model parameters are included in Fig. 4c.

\subsubsection{GFRP ribs and skin}

The GFRP materials were considered orthotropic, with linear elasticity. Their compliance matrix is indicated in equation (8), defined by engineering constants in the three principal material directions, namely: $E_{1}, E_{2}, E_{3}$ (elasticity moduli); $v_{12}, v_{13}, v_{23}$ (Poisson's ratios); and $G_{12}, G_{13}$, and $G_{23}$ (shear modules).

$$
\left[\begin{array}{l}
\varepsilon_{1} \\
\varepsilon_{2} \\
\varepsilon_{3} \\
\gamma_{4} \\
\gamma_{5} \\
\gamma_{6}
\end{array}\right]=\left[\begin{array}{cccccc}
\frac{1}{E_{1}} & \frac{-v_{21}}{E_{2}} & \frac{-v_{31}}{E_{3}} & 0 & 0 & 0 \\
\frac{-v_{12}}{E_{1}} & \frac{1}{E_{2}} & \frac{-v_{32}}{E_{3}} & 0 & 0 & 0 \\
\frac{-v_{13}}{E_{1}} & \frac{-v_{23}}{E_{2}} & \frac{1}{E_{3}} & 0 & 0 & 0 \\
0 & 0 & 0 & \frac{1}{\mathrm{G}_{12}} & 0 & 0 \\
0 & 0 & 0 & 0 & \frac{1}{\mathrm{G}_{13}} & 0 \\
0 & 0 & 0 & 0 & 0 & \frac{1}{\mathrm{G}_{23}}
\end{array}\right]\left[\begin{array}{c}
\sigma_{11} \\
\sigma_{22} \\
\sigma_{33} \\
\sigma_{12} \\
\sigma_{13} \\
\sigma_{23}
\end{array}\right]
$$

The values adopted for some of these parameters were determined from experimental tests, while the remaining ones were obtained from [11]. All these values are indicated in Tables 2 and 3.

Table 2.

Table 3

Mastali, Mohammad, Valente, Isabel B., Barros, Joaquim A. O. (2016).

Development of innovative hybrid sandwich panel slabs: Advanced numerical simulations and parametric studies.

Paper submitted to Composite Structures, Elsevier, ISSN 0263-8223. 


\section{Parametric studies and complementary analysis for the optimization of the hybrid slab system}

\subsection{Introduction}

Parametric studies were executed in two phases to approach the optimized slab's dimensions and to indicate the effects of material and geometric attributes (slab's height and thickness of each slab's component) on the global behavior of this type of slabs.

In the first stage of the parametric studies, FEM analyses were executed assuming a linearorthotropic behavior for modelling the GFRP materials. The second stage differs from the previous one only on the behavior adopted for the DHCC that was now considered nonlinear due to crack initiation and propagation. FEMIX computer program was used in these two phases.

\subsection{Parametric studies}

\subsubsection{Assumptions, loading and support conditions}

The parametric studies were executed and the following two assumptions were adopted:

1. Perfect bond was considered between GFRP ribs and DHCC layer. During the experimental tests, signs of debond were only observed at the stage of slab's maximum load carrying capacity, caused by the formation of splitting cracks in the alignment of the GFRP ribs [5];

2. The stiffness and strength contributions of the foam core were neglected due to their relatively low values.

The generic cross section geometry of the slab is represented in Fig. 1a. Mindlin shell isoparametric finite elements of 8 nodes, with $2 \times 2$ Gauss Legendre integration scheme are used in the numerical simulations [12]. Fig. 1b illustrates the support conditions, where markers indicate the points with null displacement in the vertical direction $(Z)$, while the nodes in the middle span have null displacement and rotation in $Y$ and $X$ direction, respectively, in order to simulate symmetry conditions. As already indicated, this type of

Mastali, Mohammad, Valente, Isabel B., Barros, Joaquim A. O. (2016).

Development of innovative hybrid sandwich panel slabs: Advanced numerical simulations and parametric studies.

Paper submitted to Composite Structures, Elsevier, ISSN 0263-8223. 
hybrid slab system is aimed to be used in the rehabilitation of buildings with masonry walls. In this type of buildings, the existing resisting masonry walls can, in general, provide support conditions for a slab's span ranging between 3.5 and $5 \mathrm{~m}$. Therefore, a slab's span of $4 \mathrm{~m}$ was adopted in these parametric studies. Furthermore, the main occupation expected for these buildings is of residential character, and therefore a live load of $1.5 \mathrm{kN} / \mathrm{m}^{2}$ was considered. By adopting the specific mass of the intervening materials and taking into account the results obtained in [5], an average value of $1.0 \mathrm{kN} / \mathrm{m}^{2}$ was assumed for the dead weight of the slabs, which also includes a uniformly distributed load of about $0.3 \mathrm{kN} / \mathrm{m}^{2}$ for the covering materials (ceramic or timber).

The following design criteria were considered: the maximum slab's deflection at serviceability limit state (SLS) conditions was limited to $L / 250$, as defined in EN1992-11:2004 [13]; and the maximum values in the stress fields installed in the constituent materials are limited to the governing strength capacity of these materials (compressive, tensile and shear strength for the DHCC, GFRP skin and GFRP rib, respectively).

\subsubsection{Assuming linear-elastic-orthotropic behavior for the GFRP}

By considering that the GFRP ribs are disposed in only one direction, the configuration of the slab adopted is one-way bending behavior, as represented in Fig. 1b. Additionally, the behavior of GFRP materials used for ribs and skin was assumed orthotropic. GFRP sheets with fibers oriented at $0^{\circ}$ and $90^{\circ}$ were adopted in skins, while GFRP sheets with oriented fibers at $\pm 45^{\circ}$ were chosen for ribs, in order to take into account that in these components the predominant stress field is longitudinal tension and shear, respectively. Moreover, value of 0.2 was adopted for the Poisson coefficient of the DHCC layer.

The mechanical properties considered for GFRP ribs and skins are listed in Table 4.

The DHCC was considered with a linear-elastic behavior with the properties already indicated. From this analysis, the following main conclusions can be pointed out:

Mastali, Mohammad, Valente, Isabel B., Barros, Joaquim A. O. (2016).

Development of innovative hybrid sandwich panel slabs: Advanced numerical simulations and parametric studies.

Paper submitted to Composite Structures, Elsevier, ISSN 0263-8223. 
1. By considering the support conditions that result in two-way bending, and adopting orthotropic behaviour for the GFRP materials, both the maximum normal stresses $\left(\sigma_{1}\right.$ and $\sigma_{2}$ in the directions 1 and 2, respectively, in Figs. 1c and 1d) in the GFRP ribs and skin, as well as the slab's deflection, have increased more than 2 times, in comparison to a simplified preliminary analysis that considered two-way bending behaviour of the slab and isotropic behaviour in the GFRP.

2. To accomplish the deflection limit imposed by SLS conditions, $L / 250=16 \mathrm{~mm}$, the thickness of the slab must be higher than $100 \mathrm{~mm}$.

3. By increasing the DHCC thickness, the maximum slab's deflection and maximum compressive stress in DHCC layer have decreased, while the maximum in-plane shear and the maximum normal tensile stresses have increased in both GFRP ribs and skin.

4. By increasing the thickness of GFRP ribs, the maximum compressive and tensile stresses in the DHCC layer and GFRP skin, respectively, have decreased.

5. By increasing the GFRP skin thickness, the neutral surface has moved downward, and the in-plane shear stresses in the GFRP ribs have slightly decreased.

Since GFRP materials used in the skin and ribs have linear behavior up to failure, the DHCC material is the unique component of the proposed hybrid sandwich slab that can develop nonlinear behavior, mainly due to its susceptibility to crack formation and propagation. Therefore, in the second phase of the parametric analysis, the material nonlinear behaviour of the DHCC layer was simulated.

\subsubsection{Assuming material nonlinear behavior for the DHCC}

A new parametric study was carried out by varying the slab's cross section height and the thickness of the slab's components, according to the intervals indicated in Table 4. The range of values assumed for the thickness of the slab's components investigated $(H, B, C$

Mastali, Mohammad, Valente, Isabel B., Barros, Joaquim A. O. (2016).

Development of innovative hybrid sandwich panel slabs: Advanced numerical simulations and parametric studies.

Paper submitted to Composite Structures, Elsevier, ISSN 0263-8223. 
and D) are indicated in this table. The meaning of the parameters defined in Table 4 is represented in Fig. 1a.

Table 4.

In a first step of the analysis, the load combination corresponds to a service load level. It considers the addition of the permanent load, PL, (slab's dead load plus a load corresponding to the covering materials, $1 \mathrm{kN} / \mathrm{m}^{2}$ ) with the live load, $\mathrm{LL}$, resulting in $\mathrm{PL}+\mathrm{LL}$. Relevant results obtained with the FEM material nonlinear analysis can be pointed out:

1. Increasing the thickness of a slab's component results in reducing the maximum stress in that same component, while the maximum stresses increased in other slab's components where the thickness was kept constant. For instance, increasing the thickness of DHCC layer led to an increase of the maximum in-plane shear stress on GFRP ribs and tensile stress in GFRP skin, while the maximum compressive stress in DHCC layer decreased (see Figs $5 b$ to $5 d$ ).

2. A maximum reduction of stress was found when the thickness of the GFRP ribs was increased.

Fig. 5

To assess the effects of thickness variation on the maximum values of the stress fields installed in the constituent materials and on the obtained ultimate load carrying capacity of hybrid slabs, the slabs were also loaded under a load combination that included the permanent load and the live load. The permanent load, PL (slab's dead load plus a load corresponding to the covering materials, $1 \mathrm{kN} / \mathrm{m}^{2}$ ) was applied to the slabs, and then the live load was imposed and increased up to a predefined limit, where the total load is defined by $P L+\alpha L L$, with alpha $(\alpha)$ being higher than 1 and $L L=1.5 \mathrm{kN} / \mathrm{m}^{2}$. This limit resulted from one of the following design criteria [13]:

1. A maximum crack width of $0.3 \mathrm{~mm}$ in the DHCC layer.

Mastali, Mohammad, Valente, Isabel B., Barros, Joaquim A. O. (2016).

Development of innovative hybrid sandwich panel slabs: Advanced numerical simulations and parametric studies.

Paper submitted to Composite Structures, Elsevier, ISSN 0263-8223. 
2. The material strength limit is reached in one of the slab's components (compressive strength of $24 \mathrm{MPa}$ for the DHCC; tensile strength of 1000 and $30 \mathrm{MPa}$ in 1 and 2 material directions, respectively, for the GFRP skin; in-plane shear strength of $100 \mathrm{MPa}$ for the GFRP rib).

3. A slab's mid-span deflection of $L / 250=16 \mathrm{~mm}$.

The maximum crack width was numerically computed by multiplying the crack bandwidth, $I_{c r}$, (Table 1), by the maximum normal crack strain determined in the integration points (Ips) [12]. According to EN 1992-1-1:2004, the maximum crack width should be limited to $0.3 \mathrm{~mm}$ under service load conditions [13].

The numerical results obtained are related to the maximum load level attained, which is limited by the design criteria previously listed and pointed out in Fig. 5 . The following aspects can be highlighted:

1. Increasing the thicknesses of slab's components resulted in increasing the distributed load that is applied to the slabs (see Fig. 5a).

2. Increasing the thickness of each slab's component results in reducing the maximum stress in that slab's component, which that the thickness increased. While the maximum stresses in the other slab's components that the thicknesses were kept constant increased.

3. Increasing the thickness of GFRP ribs has a significant impact on increasing the alpha ( $\alpha$ ) factor in comparison to increasing the thickness of the GFRP skin or the thickness of the DHCC layer.

4. The minimum hybrid slab's height that meets the design requirements is limited to $100 \mathrm{~mm}$ height.

5. Increasing the thickness of DHCC layer leads to a reduction of the crack width (see Fig. 5e) and the number of formed cracks (see Fig. 6).

Mastali, Mohammad, Valente, Isabel B., Barros, Joaquim A. O. (2016).

Development of innovative hybrid sandwich panel slabs: Advanced numerical simulations and parametric studies.

Paper submitted to Composite Structures, Elsevier, ISSN 0263-8223. 
Fig. 6

\subsection{Buckling verifications}

Using relatively thin GFRP ribs to transfer shear stresses from top DHCC layer to bottom GFRP skin increased the possibility of localized buckling in the webs due to in-plane shear and compressive stresses. The possibility of local buckling in the GFRP ribs was investigated through equations that consider the contribution of the compressive and inplane shear stresses [14]. Since a direct simulation of buckling phenomenon in FEMIX software was not possible, equations (9) to (15) were used to consider the contribution of compressive stresses in the buckling of GFRP ribs [15],

$$
\begin{gathered}
\sigma=\frac{\pi^{2}}{t_{R} d_{R}{ }^{2}}\left(13.9 \sqrt{D_{R 1} D_{R 2}}+11.1 D_{R 12}+22.2 D_{R S}\right) \\
D_{R 1}=\frac{E_{R 1} t_{R}{ }^{3}}{12\left(1-v_{R 1} v_{R 2}\right)} \\
D_{R 2}=\frac{E_{R 2} t_{R}{ }^{3}}{12\left(1-v_{R 1} v_{R 2}\right)} \\
D_{R 12}=v_{R 1} D_{R 2}=v_{R 2} D_{R 1} \quad v_{R 2}=\frac{E_{1}}{E_{2}} v_{R 1} \\
D_{R S}=\frac{G_{R_{12}} t_{R}^{3}}{12} \\
\sigma_{c r i t i c a l}=\frac{\sigma}{\gamma_{m}} \\
\gamma_{m}=\gamma_{m 1} * \gamma_{m 2} * \gamma_{m 3}
\end{gathered}
$$

where, $E_{R 1}, E_{R 2}$ are the Young's modulus of the GFRP rib in 1 and 2 material axis, as shown in Fig. $1 \mathrm{c}, \mathrm{d}_{\mathrm{R}}$ is the rib height, $G_{R 12}$ is the shear modulus of the rib (based on Table 4 , this value was considered equal to $8 \mathrm{GPa}$ ), $t_{R}$ is the rib thickness, and $\gamma_{m}$ is a safety factor. The material partial safety factor, $\gamma_{m}$, was computed based on the EUROCOMP design guide [16]. The values of $1.15,1.1$, and 2.5 , were considered to approach, respectively, the material property data $\left(\gamma_{m 1}\right)$, the material manufacturing process $\left(\gamma_{m 2}\right)$, and the effects of environmental variables and the duration of the loading period $\left(\gamma_{m 3}\right)$ [16]. By multiplying these three coefficients, a safety factor of 3.16 was obtained [14].

Mastali, Mohammad, Valente, Isabel B., Barros, Joaquim A. O. (2016).

Development of innovative hybrid sandwich panel slabs: Advanced numerical simulations and parametric studies.

Paper submitted to Composite Structures, Elsevier, ISSN 0263-8223. 
Moreover, the critical in-plane shear stress $\left(\tau_{\text {Critical }}\right)$ in the ribs can be computed with equations (16) to (19) [14].

$$
\begin{gathered}
\tau=\frac{4 K_{12} \sqrt[4]{D_{R 1} D_{R 2}{ }^{3}}}{t_{R} d_{R}{ }^{2}} \\
K_{12}=8.125+5.045 K, \text { for } K \leq 1 \\
K=\frac{\left(2 D_{R S}+D_{R_{12}}\right)}{\sqrt{D_{R 1} D_{R 2}}} \\
\tau_{\text {Critical }}=\frac{\tau}{\gamma_{m}}
\end{gathered}
$$

For the orthotropic materials used in conventional GFRP profiles, the $K$ value adopted is equal or lower than one. For isotropic materials, $K$ is considered equal to one [14, 23]. Since a linear orthotropic behavior was adopted for modelling GFRP materials, $\mathrm{K}$ can be considered equal or lower than one, in equation (17).

\subsection{Optimized slab's cross section}

The effect of each parameter on the slab's global behavior was investigated during the parametric study. Based on the results obtained, seven slabs were selected among the large group evaluated and proposed for further analysis. The dimensions of the proposed seven slabs are listed in Table 5.

\section{Table 5 .}

The seven hybrid slabs proposed were analyzed in order to select the ones that present the best structural performance and cost effectiveness. First, the permanent load was imposed to the slabs in order to determine the relevant deflection. Then, a live load equal to $1.5 \mathrm{kN} / \mathrm{m}^{2}$ was applied and this load was increased up to the criteria already indicated in paragraph 3.2.3, namely:

1. Attainment of a maximum crack width of $0.3 \mathrm{~mm}$ in DHCC layer;

Mastali, Mohammad, Valente, Isabel B., Barros, Joaquim A. O. (2016).

Development of innovative hybrid sandwich panel slabs: Advanced numerical simulations and parametric studies.

Paper submitted to Composite Structures, Elsevier, ISSN 0263-8223. 
2. Attainment of the strength limits of slab's components: compressive strength of $24 \mathrm{MPa}$ for the DHCC; tensile strength of 1000 and $30 \mathrm{MPa}$ in 1 and 2 material directions, respectively, for the GFRP skin; in-plane shear strength of $100 \mathrm{MPa}$ for the GFRP rib;

3. Slab's mid-span deflection of $L / 250=16 \mathrm{~mm}$.

The results obtained during the numerical analysis of the proposed seven hybrid slabs are presented in Table 5. The possibility of buckling phenomenon in GFRP ribs was also checked by calculating the compressive and the in-plane shear stresses. The results listed in Table 6 show that buckling of ribs does not occur in the proposed hybrid slabs.

Table 6.

The combination of cost effectiveness and structural safe behavior were considered the main criteria to select the optimized slabs. Therefore, a preliminary cost analysis was carried out on the proposed hybrid slabs to attain the cost of slabs, by considering the price for the constituent materials, as provided by the corresponding suppliers. The price of Slab 1 (SGO 3) and Slab 2 (SMO 1) was estimated at about $150 € / \mathrm{m}^{2}$ and $130 € / \mathrm{m}^{2}$, respectively, while the price of conventional solutions in concrete slabs was estimated in the interval 140-180 $€ / \mathrm{m}^{2}$ in [22]. Then, with respect to the results obtained from execution of cost analysis and parametric studies, two hybrid slabs (SMO 1 and SGO 3) were chosen as the optimized hybrid slabs. Afterwards, the two optimized slabs indicated in Fig. 7 were manufactured and experimentally tested at University of Minho. The dimensions and the materials used in each slab's component are listed in Table 7.

Fig 7.

Table 7.

\section{Experimental tests performed on the proposed hybrid slabs}

Two hybrid slabs with span length of $1.8 \mathrm{~m}$ were loaded under cyclic four point bending load conditions by applying a displacement rate of $30 \mu \mathrm{m} / \mathrm{s}$ [5]. Flexural loading was applied to the slabs through two load lines with $40 \mathrm{~mm}$ width and $800 \mathrm{~mm}$ length (corresponding to the

Mastali, Mohammad, Valente, Isabel B., Barros, Joaquim A. O. (2016).

Development of innovative hybrid sandwich panel slabs: Advanced numerical simulations and parametric studies.

Paper submitted to Composite Structures, Elsevier, ISSN 0263-8223. 
slabs' total width). This load line was located at $600 \mathrm{~mm}$ distance from each support. A schematic figure of the tested hybrid slabs and the used monitoring devices is presented in Fig. 8. Seven LVDTs were used to measure deflection and slip in different locations of the slabs. Moreover, eight strain gauges (SG) were used in different positions of the slabs to measure strain values [5].

Fig 8.

The first phase of loading for Slab 1 consisted on the application of two cycles with a maximum mid-span deflection of $14.4 \mathrm{~mm}$. During this first load sequence, Slab 1 presented signs of damage. Therefore, in order to have a first load sequence with a linear response, the increment of deflection adopted in Slab 2 was limited to $7.2 \mathrm{~mm}$ [5].

In Slab 1, material damage occurred in GFRP ribs due to excessive compressive stress, leading to a hardening behavior for a deflection above $5.5 \mathrm{~mm}$, where no sliding and uplift were registered [5]. In Slab 2, compressive damage (material failure) occurred in the GFRP ribs for a deflection of about $7.5 \mathrm{~mm}$ [5]. Furthermore, splitting crack was formed on the surface of the DHCC layer. Slab 2 entered in a structural softening stage immediately before the second cycle of the second load sequence and GFRP ribs slipped and uplifted from its embedded DHCC layer [5]. No local or global buckling failure occurred in the GFRP ribs of both hybrid slabs during the experimental tests [5].

The recorded experimental results in terms of force-deflection response, force-strain response, and the observed damages of the hybrid slabs are used to calibrate the FEM 3D models [5].

Advanced numerical simulations of the experimental tests were carried out on the first phase of loading applied to Slab 1 and to Slab 2. During the experimental tests, damage occurred in different load levels. Therefore, using proper constitutive models and adequate interface surfaces for slab's components could well be the way to capture the damage observed and the flexural response of the tested hybrid sandwich panels.

Mastali, Mohammad, Valente, Isabel B., Barros, Joaquim A. O. (2016).

Development of innovative hybrid sandwich panel slabs: Advanced numerical simulations and parametric studies.

Paper submitted to Composite Structures, Elsevier, ISSN 0263-8223. 


\section{Advanced numerical simulations of the proposed hybrid slabs}

The three-dimensional FE model indicated in section 2.3 was used for simulating the experimental tests carried out with the proposed hybrid slabs.

Contact surface properties are especially important on the numerical simulation of hybrid slabs because the structural performance of composite slabs depends on the properties of the contact surface between slab's components. There are three different contact surfaces that may be considered in the proposed hybrid slabs: between foam and GFRP ribs and skin, between foam and DHCC layer, and between GFRP ribs and DHCC layer.

During the experimental tests, foam cores detached from DHCC layer without any significant influence on the slab stiffness. Compressive damage in GFRP ribs and crack formation on the top surface of the DHCC layer were observed in the experimental tests and should be well captured in the numerical models. In these numerical simulations, a Cohesive Zone Model (CZM) was used to simulate the interface between slab's components. The cohesive zone model is able to predict adequately the behavior of cracked and uncracked cementitious composites. This model was used successfully to predict the behavior of other materials such as fiber reinforced polymers [25]. CZM follows a softening path with the peak traction at the start of separation process [26].

One contact surface was used for the GFRP ribs embedded within the DHCC material, and another contact surface was defined between DHCC material and foam core. The cohesive surfaces behave in a quasi-rigid way up to the initiation of damage. Failures at each interface were allowed to occur between the embedded GFRP ribs and the DHCC layer and also between the DHCC layer and the foam cores. No slip was detected between foam cores and GFRP skin or ribs during the experimental tests and, therefore, perfect bond was assumed adequate to model the contact between foam cores and GFRP skin or ribs.

To assess the adequacy and the accuracy of interface models, two different approaches were used in the numerical simulations with the tested hybrid slabs. The first approach

Mastali, Mohammad, Valente, Isabel B., Barros, Joaquim A. O. (2016).

Development of innovative hybrid sandwich panel slabs: Advanced numerical simulations and parametric studies.

Paper submitted to Composite Structures, Elsevier, ISSN 0263-8223. 
considers the different interfaces between slab's components, as already mentioned, and the second approach assumes perfect bond between the slab's components. These two approaches are considered because the computational demand of considering interface models between contact surfaces is much higher than assuming perfect bond.

Fig. 9a shows an illustration of a simple bilinear traction-separation constitutive law that is governed by the stiffness $K_{0}$, maximum traction $\tau_{\max }$, and cohesive fracture energy $G_{\mathrm{cr}}$. The $G_{\mathrm{cr}}$ is the required energy to complete the debonding between contact surfaces, and it is equal to the area under the traction $(\tau)$ - separation $(\delta)$ curve up to the ultimate separation $\left(\delta_{f}\right)$. Contact with cohesive behavior (traction-separation law) was used to model the interface between DHCC layer, foam core, and GFRP rib. In this study, the mixed bilinear cohesive zone model, containing normal and shear components (see Fig. 9b), was chosen for computational convenience.

Fig 9.

The quadratic stress criterion is defined in equation (20), where, $\sigma_{n}$ is the cohesive tensile stress and $\tau_{1}$ and $\tau_{2}$ are the shear stresses in normal directions, 1 and 2, respectively (see Fig. 9b). Moreover, in equation (20), $\sigma_{n}{ }^{0}$ is the cohesive tensile strength and $\tau_{1}{ }^{0}$ and $\tau_{2}{ }^{0}$ are the shear strengths in normal directions, 1 and 2, respectively.

Damage in the bilinear cohesive zone model was assumed to occur when a quadratic traction function involving the nominal stress ratios reaches the value one [18]. A typical mixed-mode response is depicted in Fig. $9 \mathrm{~b}$, in which points marked as $A$ and $B$ correspond to the initiation of damage and full failure conditions of mixed-mode response that are defined based on the mixed-mode damage initiation defined with equation (20) and propagation criteria defined with equation (21), respectively. The dependence of the fracture energy on the mix mode was based on the Benzaggah-Kenane (BK) damage evolution criterion. Equations (20) and (21) represent the Benzeggah-Kenane damage evolution criterion, where $G_{l,} G_{\|}$and $G_{\| /}$refer to the fracture toughnesses and so that $G_{/}$is derived

Mastali, Mohammad, Valente, Isabel B., Barros, Joaquim A. O. (2016). parametric studies.

Paper submitted to Composite Structures, Elsevier, ISSN 0263-8223. 
from the opening mode and $G_{\|}$and $G_{\| I}$ are related to sliding and tearing modes, respectively. Moreover, $\mathrm{G}_{\mathbb{I C}}$ and $\mathrm{G}_{\| \mathrm{C}}$ are the critical fracture energies for mode I and mode II, respectively. The critical fracture energies are represented by the area under the bilinear traction-separation curve for the representative mode, as indicated in Fig. 9b. The energybased Benzeggah and Kenane (BK) damage evolution criterion was used as the propagation criterion [6]. In equation (21), $\eta$ is a BK material parameter and the corresponding value adopted is 2 [19]. Damage propagation criterion under the mixed bilinear cohesive zone model expressed in terms of the total fracture energy release rates, $G_{T}$ and single mode critical energy release of the interface, $G_{\|}, G_{\|}$, and $G_{\| I}$ such that $\mathrm{G}_{T}=\mathrm{G}_{1}+\mathrm{G}_{\|}+\mathrm{G}_{\| \mid}$is given in equation (21).

$$
\begin{gathered}
\left(\frac{\sigma_{n}}{\sigma_{n}^{0}}\right)^{2}+\left(\frac{\tau_{1}}{\tau_{1}^{0}}\right)^{2}+\left(\frac{\tau_{2}}{\tau_{2}^{0}}\right)^{2}=1 \\
G_{I}+G_{I I}=G_{I C}+\left(G_{I I C}-G_{I C}\right)\left(\frac{G_{\text {shear }}}{G_{T}}\right)^{\eta} \\
G_{\text {shear }}=G_{I I}+G_{I I I} \\
G_{T}=G_{I}+G_{I I}+G_{I I I}
\end{gathered}
$$

The energy release rates under mixed-mode critical condition can be computed by the given equation (24) (see Fig. 9c):

$$
\begin{array}{ll}
G_{I}=\frac{1}{2}\left(K_{0}\right)_{I} \times\left(\delta_{0 \text { mix }}\right)_{I} \times\left(\delta_{f \text { mix }}\right)_{I} \quad G_{I C}=\frac{1}{2}\left(K_{0}\right)_{I} \times\left(\delta_{0 \text { pure }}\right)_{I} \times\left(\delta_{f \text { pure }}\right)_{I} \\
G_{I I}=\frac{1}{2}\left(K_{0}\right)_{I I} \times\left(\delta_{0 \text { mix }}\right)_{I I} \times\left(\delta_{\text {f mix }}\right)_{I I} & G_{I I C}=\frac{1}{2}\left(K_{0}\right)_{I I} \times\left(\delta_{0 \text { pure }}\right)_{I I} \times\left(\delta_{\text {f pure }}\right)_{I I}
\end{array}
$$

where, $\left(\mathrm{K}_{0}\right)_{\mathrm{I}}$ is the stiffness for mode $\mathrm{I},\left(\mathrm{K}_{0}\right)_{\|}$is the stiffness for mode II, $\left(\delta_{0 \text { mix }}\right)_{I}$ is separation at the onset softening of the mixed-mode $\mathrm{I},\left(\delta_{\mathrm{f} \text { mix }}\right)_{\mathrm{I}}$ is the ultimate separation in the mixedmode I, $\left(\delta_{0 \text { mix }}\right)_{\|}$is separation at the onset softening of the mixed-mode II, $\left(\delta_{f \text { mix }}\right)_{\|}$is the ultimate separation in the mixed-mode $\mathrm{II},\left(\delta_{0} \text { pure) }\right)_{\mathrm{I}}$ is separation at the onset softening of the pure mode $I,\left(\delta_{f} \text { pure }\right)_{I}$ is the ultimate separation in the pure mode $I,\left(\delta_{0} \text { pure }\right)_{I I}$ is separation at 
the onset softening of the pure mode $I$, and $\left(\delta_{f \text { pure }}\right)_{\|}$is the ultimate separation in the pure mode II.

Various studies have been undertaken on the FRP-concrete bonded interfaces and there are available parameters in bilinear cohesive zone model, such as initial stiffness, the traction and an interval for fracture energy $[19,20]$.

To the authors' best knowledge, there is only one study reported on the literature related to the experimental bond response of GFRP shear connectors embedded in reinforced concrete hybrid structures [21], but there is not any work in the literature on the bond response between the proposed GFRP shear connectors and reinforced mortars, and also between foam core and reinforced mortars in hybrid structures. The bilinear CZM parameters are completely unknown, as they depend on the bond interaction between three materials (GFPR rib, foam core, and DHCC material) and no well-established tractionseparation curves are available.

Thus, an inverse analysis procedure was executed with ABAQUS software in order to obtain the unknown parameters of the bilinear cohesive zone model. This analysis was carried out to best-fit the experimental results in terms of force-deflection and force-strain relationships, and to well capture of the observed damages.

\subsection{FEM mesh, loading and support conditions}

Four-node constant strain tetrahedral elements (C3D4) with one integration point were used to model the DHCC materials. Mesh refinement was adopted in zones of expected high gradient of stress fields, such is the case around the GFRP shear connectors (see Fig. 10a). GFRP rib and skin were also simulated using 4-node constant strain tetrahedral elements. Six-node linear triangular prism elements (C3D6) with two integration points were used to simulate the foam cores.

Fig. 10

Mastali, Mohammad, Valente, Isabel B., Barros, Joaquim A. O. (2016).

Development of innovative hybrid sandwich panel slabs: Advanced numerical simulations and parametric studies.

Paper submitted to Composite Structures, Elsevier, ISSN 0263-8223. 
The proposed hybrid slabs have double symmetry. Therefore, only one quarter of the slab was modeled. The DHCC layers, GFRP rib, GFRP skin, and foam cores of Slab 1 were respectively modeled with 16011, 4652, 8212, and 20272 elements, while in Slab 2 these elements were modeled with 17763, 3999, 7788, and 15120 elements, respectively. The required computation time for analyzing Slab 1 and Slab 2 in ABAQUS software was 1:24 hour (CPU time) and 1:14 hour, respectively.

As shown in Fig. 10a, a finer mesh was considered around the GFRP shear connectors to obtain results with sufficient accuracy, where relatively high stress gradients are expected to occur. The boundary conditions used in the numerical simulations are illustrated in Fig. 10d. The displacement in the X-axis is restricted on one surface of a quarter of slab and the displacement in direction of Z-axis is restricted on the other surface. Moreover, Fig. 10d illustrates the support condition, where diamond markers indicate the points with null displacement in the vertical direction $(\mathrm{Y})$.

In the experimental tests, the flexural load was imposed to the hybrid slabs through two load lines. These dispositions were copied to the numerical model. The total applied deflection in each slab was divided into a series of deflection increments. Newton-Raphson incrementaliterative method was adopted by evaluating the tangent stiffness matrix, in each iteration. A tolerance of 0.001 was adopted for assuring convergence.

\subsection{Failure criteria}

Two types of failure were observed in the tested hybrid slabs: 1) Stability failure, based on local buckling in the ribs; 2) Material failure, e.g. DHCC under tension or compression, compression rib crushing or tension rib rupture, and tension skin rupture. Stability failure was found when a very large displacement suddenly occurs in the slab. Material failure was found when the maximum stress measured on a specific component was higher than the ultimate tensile and compressive strengths of the corresponding material (see Table 1 and

Mastali, Mohammad, Valente, Isabel B., Barros, Joaquim A. O. (2016).

Development of innovative hybrid sandwich panel slabs: Advanced numerical simulations and parametric studies.

Paper submitted to Composite Structures, Elsevier, ISSN 0263-8223. 
Table 2). It is worth stating that no damage was observed in the foam cores during the tests [5], therefore, material failure was considered only for exceeding the maximum stress measured in the DHCC layer, GFRP ribs, and GFRP skin from the ultimate tensile and compressive strengths of the corresponding material.

\subsection{Results and discussion}

In order to define the bilinear traction-separation constitutive law, three parameters must be determined: stiffness $\left(\mathrm{K}_{0}\right)$, bond strength $\left(\tau_{\max }\right)$, and fracture energy $\left(G_{\mathrm{f}}\right)$. Moreover, to use the bilinear traction-separation constitutive law, it is necessary to define the parameters of damage initiation. As there is no data on the literature related to the bond behavior between the proposed GFRP shear connectors and reinforced mortars, the unknown values of the CZM parameters were obtained by executing an inverse analysis.

The unknown parameters of the bilinear traction-separation constitutive law and the parameters of damage initiation were determined for both tested hybrid slabs, by adopting the error of the force-deflection response of the numerical simulation lower than $8 \%$ and fitting as better as possible the force-strain relationship registered experimentally. Moreover, the damages observed in the numerical simulations should be consistent with the experimental results. Table 8 indicates the parameters of the bilinear traction-separation constitutive law and the damage initiation obtained from in the inverse analysis. Further experimental analysis is needed to establish the reasons for the differences between Slab 1 and Slab 2 in the parameters of the bilinear traction-separation constitutive law and the damage initiation. It is supposed that they are caused by the differences in the thicknesses and in the mechanical properties of the GFRP material used in the ribs.

Table 8.

Mastali, Mohammad, Valente, Isabel B., Barros, Joaquim A. O. (2016).

Development of innovative hybrid sandwich panel slabs: Advanced numerical simulations and parametric studies.

Paper submitted to Composite Structures, Elsevier, ISSN 0263-8223. 


\subsubsection{Failure modes}

In Fig. 11, the force-deflection response obtained in the numerical simulation of the hybrid slabs with perfect bond between components was compared with the results obtained in hybrid slabs that employed CZM.

During the first cycle of the loading procedure applied in the experimental test of Slab 1, compressive damage in GFRP ribs was recorded, at a deflection of $5.5 \mathrm{~mm}$, as described in [5]. Above the deflection of $5.5 \mathrm{~mm}$, a hardening stage began, caused by deflection hardening behavior of the reinforced mortar layer and the perforated shear connectors. Point A in Fig. 11a corresponds to the initiation of slip between GFRP ribs and DHCC layer.

\section{Fig. 11}

During the first cycle of the loading procedure applied in Slab 2, in addition to compressive damage in GFRP ribs, splitting cracks were formed on the surface of DHCC layer. Moreover, slip and uplift movements were registered between the GFRP ribs and DHCC layer in Slab 2.

To assess the bond behavior of the interface surfaces introduced between the slab's components, the damage formed in the CZM was detected with the quadratic stress criterion defined by equation (15). Cohesive tensile stress $\left(\sigma_{n}{ }^{9}\right)$ and shear stresses in normal directions, 1 and $2\left(\tau_{1}{ }^{0}\right.$ and $\left.\tau_{2}{ }^{0}\right)$ were defined through an inverse analysis and listed in Table 8 for Slab 1 and Slab 2.

In the numerical model developed for Slab 1, the maximum shear stress in the interface surface between the DHCC layer and the GFRP ribs was $9.08 \mathrm{MPa}$, while the shear strength in the defined CZM was $10 \mathrm{MPa}$. This means that damage is close to be initiated in the contact surface between the DHCC layer and the GFRP ribs.

In the numerical model developed for Slab 2, the maximum shear stress measured at the interface surface between the DHCC layer and the GFRP ribs was $7.67 \mathrm{MPa}$, which is higher than the shear strength established and shows the damage formed in the defined

Mastali, Mohammad, Valente, Isabel B., Barros, Joaquim A. O. (2016).

Development of innovative hybrid sandwich panel slabs: Advanced numerical simulations and parametric studies.

Paper submitted to Composite Structures, Elsevier, ISSN 0263-8223. 
CZM (see Table 8). The FE model could also capture the uplift and the slip between DHCC layer and GFRP rib in Slab 2, as shown in Fig. 12a and Fig. 12c.

Fig. 12

ABAQUS software does not provide a failure criterion for composite materials modeled with solid elements. In the absence of failure criterion for the modelled composite materials with solid elements in ABAQUS software, it was not possible to capture the pseudo-plastic stage of the slabs in the FEM 3D models developed. By using the maximum stress and maximum strain criteria for the modelled composite materials with solid elements, the FEM 3D models could capture the structural behavior of hybrid slabs up to initiation of damage in GFRP ribs. Thus, failures in the solid elements of GFRP materials were found by comparing the maximum stresses and strains obtained in the elements with the capacity of the materials in terms of stresses and strains, presented in Table 2.

According to the strains recorded with strain gauges installed in the GFRP ribs, compressive damage occurred in GFRP ribs of Slab 1 and Slab 2 due to high compressive strain values, 0.00026 and 0.0003 , respectively [5]. The maximum compressive strains in the GFRP ribs (SG 1) obtained in the FE models were 0.0004 in Slab 1 and 0.00038 in Slab 2. In both cases, the strain values measured in the numerical models were higher than the strains measured in the corresponding experimental tests (see Fig. 14).

The DHCC material was experimentally evaluated and the corresponding results are presented in [5]. Its compressive strength measured about $24 \mathrm{MPa}$. The maximum compressive stress obtained in the FE model was $23.8 \mathrm{MPa}$ in Slab 1 and $26.7 \mathrm{MPa}$ in Slab 2 under the load line (see Fig. 12g). According to the values mentioned, the DHCC layer was nearly damaged due to high compressive stresses in Slab 1, under the load line, while the DHCC layer in Slab 2 has entered in a post peak phase.

Fig. 13 presents the distribution of longitudinal principal stresses and in-plane shear stresses in the GFRP ribs. The captured damages in the shear connectors and GFRP ribs of the numerical results are consistent with the experimental ones, as indicated in Fig. 13.

Mastali, Mohammad, Valente, Isabel B., Barros, Joaquim A. O. (2016).

Development of innovative hybrid sandwich panel slabs: Advanced numerical simulations and parametric studies.

Paper submitted to Composite Structures, Elsevier, ISSN 0263-8223. 
Fig. 13

Concerning the presented results, it can be concluded that the developed 3D FE models can well capture the failure modes registered in the experimental tests, and have high potential to predict the flexural performance of the proposed hybrid slabs.

\subsubsection{Load-deflection response}

Fig. 11 depicts the load vs deflection responses obtained in the numerical simulations of the experimentally tested slabs. It can be observed that the results obtained in the numerical simulations have good agreement with the experimental ones. However, there is some tendency to overestimate stiffness in the FE simulation, which may be derived from the possible effect of interface slips [27].

Furthermore, the stiffness of slabs was assessed with Timoshenko beam theory, which is able to predict the stiffness of hybrid slabs under FPB load, accounting for flexural and shear deformations [5]. Equation (25) presents Timoshenko beam theory for predicting the stiffness of slabs under flexural FPB test,

$$
\Delta=\frac{\left(23 P L^{3}\right)}{(648 E I)_{\text {Total }}}+\left(\frac{P L}{3 K G A}\right)_{R i b}
$$

where, in equation (25), $P$ is the applied load, $L$ is the slab span, $E l$ is the flexural stiffness which was calculated using transformed cross-section analysis (in calculation of this value, effects of all materials were considered, including foam cores, DHCC layer, GFRP ribs and GFRP skin), $G_{\text {rib }}$ is the shear modulus of the GFRP ribs, and $A$ is the cross section of the ribs.

In equation (25), it was assumed that shear stresses are transferred between top and bottom skins by GFRP ribs while foam cores have no contribution within transferring shear stresses.

Mastali, Mohammad, Valente, Isabel B., Barros, Joaquim A. O. (2016).

Development of innovative hybrid sandwich panel slabs: Advanced numerical simulations and parametric studies.

Paper submitted to Composite Structures, Elsevier, ISSN 0263-8223. 
Both experimental and analytical responses of the proposed hybrid slabs under four point bending test are indicated in Fig. 11. Respect to the indicated results, it is revealed that the analytical estimation has good agreement with the experimental results in the linear stage.

Table 9 lists the calculated error percentages, which may be defined in terms of force, deflection, or stiffness. Table 9 evaluates the accuracy of perfect bond or CZM as interface surfaces between slab's components.

Table 9.

As was expected, using CZM as interface between slab's components led to attain smaller errors in force, deflection and stiffness values than using perfect bond between slab's components. Errors are lower than $8 \%$ for force, $7 \%$ for deflection, and $5 \%$ for stiffness for CZM interface, while perfect bond presents an error lower than $20 \%$ for force, $30 \%$ for deflection, and $10 \%$ for stiffness. Since the use of CZM significantly increases the models' computational cost, it is concluded that the use of perfect bond also results in an acceptable response for pre-design purposes, with enough reasonable accuracy in engineering applications.

\subsubsection{Load-strain response}

The recorded experimental and numerical load-strain responses of the tested hybrid slabs are shown in Fig. 14. The tensile strains did not exceed 0.0012 in both slab skins, which is well below the tensile failure strain of 0.0222 in skin fibers oriented at $90^{\circ}$, and 0.0166 in skin fibers oriented at $0^{\circ}$. This fact confirms that no tensile failures occurred in the GFRP skin.

Fig 14.

According to the results obtained, a good agreement was achieved between the experimental and the numerical simulations, with exception for the values registered by SG 3 and SG 2. The thicknesses of GFRP ribs and GFRP skin were increased in the connection zone to obtain a continuous uniform distribution of stresses and forces (see Fig. 15b). These

Mastali, Mohammad, Valente, Isabel B., Barros, Joaquim A. O. (2016).

Development of innovative hybrid sandwich panel slabs: Advanced numerical simulations and parametric studies.

Paper submitted to Composite Structures, Elsevier, ISSN 0263-8223. 
higher thicknesses in the transition zone could be the cause for the differences between experimental and numerical strain values in SG 3 and SG 2 (see Fig. 15a).

When comparing the numerical and the experimental results, it is important to note that the general tendency is to have smaller compressive experimental strains than expected and higher tensile experimental strains than expected. This is a common trend for Slab 1 and Slab 2.

Fig 15.

\section{Conclusions}

In this study, an initial parametric study was carried out to reveal the influence of material properties and geometry on the global behavior of full-scale hybrid slabs. Then, some optimized slabs were proposed and analyzed and finally, two slabs were chosen. The two optimized slabs were previously manufactured and tested experimentally at University of Minho. Then, the obtained experimental specimens and results were considered in the development of FEM models that could well capture the observed damages, and predict the force/deflection or the force/strain responses of the hybrid sandwich panels. The main outcome results of this numerical study are herein presented:

1. The parametric study demonstrated that the GFRP rib thickness is the most important slab component in increasing the load carrying capacity of hybrid slabs.

2. The minimum height of hybrid slab should be $100 \mathrm{~mm}$.

3. It is not possible to occur local buckling in the GFRP ribs under SLS.

4. Applying the interface constitutive model for bond behavior between the slab's components had significant importance in achieving a robust and more precise numerical simulation.

5. As there is no specific closed-form design code for hybrid slabs, and because the used shear connection system presents high stiffness up to the initiation of damage, using

Mastali, Mohammad, Valente, Isabel B., Barros, Joaquim A. O. (2016).

Development of innovative hybrid sandwich panel slabs: Advanced numerical simulations and parametric studies.

Paper submitted to Composite Structures, Elsevier, ISSN 0263-8223. 
perfect bond between the slab's components can be a reliable and helpful option for pre-design purposes.

6. Using the interface constitutive model resulted in attaining more accurate results but increased significantly the computational cost and time. Therefore, using perfect bond as interface between slab's components led to results with lower accuracy, in compare to the use of CZM. However, using perfect bond can reduce significantly the computational cost and time associated with these models.

\section{Acknowledgements}

The study presented in this paper is a part of the research project "RehabGFRP Rehabilitation of Building Floors with Lightweight High Performance GFRP Sandwich Panels", with reference number of PTDC/ECM/113041/2009. Furthermore, the authors honestly appreciate the collaboration of the following institutions: Civitest for developing DHCC materials and PIEP for conducting VARTM process.

\section{References}

1. Ziad K. Awad, Aravinthan T., Zhuge Y., 2012, "Experimental and numerical analysis of an innovative GFRP sandwich floor panel under point load", Journal of Engineering Structures, Vol. 41, pp: 126-135.

2. Raj S., Kumar R., Bharath Kumar B.H., Gopinath S., Iyer N.R., 2015, "Flexural studies on Basalt Fiber Reinforced Composite sandwich panel with profile sheet as core", Journal of Construction and Building Materials, Vol. 82, pp: 391-400.

3. Mostafa A., Shankar K., Morozov E.V., 2013, "Effect of shear keys diameter on the shear performance of composite sandwich panel with PVC and PU foam core: FE study", Journal of Composite Structures, Vol. 102, pp: 90-100.

Mastali, Mohammad, Valente, Isabel B., Barros, Joaquim A. O. (2016).

Development of innovative hybrid sandwich panel slabs: Advanced numerical simulations and parametric studies.

Paper submitted to Composite Structures, Elsevier, ISSN 0263-8223. 
4. Sharaf T., Fam A., 2013, "Analysis of large scale cladding sandwich panels composed of GFRP skins and ribs and polyurethane foam core", Journal of Thin-Walled Structures, Vol. 71, pp: 91-101.

5. Mastali M., Valente I.B., Barros J.A.O., Gonçalves D.M.F., 2015, "Development of innovative hybrid sandwich panel slabs: Experimental results" Journal of Composite Structures, Vol. 133, pp: 476-498.

6. Hibbitt, Karlsson, and Sorensen, Inc. ABAQUS Theory manual, User manual and Example Manual, Version 6.11., 2010, USA.

7. Barros J.A.O., Figueiras J.A., 2001, "Nonlinear analysis of steel fibre reinforced concrete slabs on grade", Journal of Computers and Structures, Vol. 79, pp: 97-106.

8. Pereira E.B., Barros, J.A.O., Camões A.F.F.L., 2008, "Steel fiber reinforced selfcompacting concrete - experimental research and numerical simulation", ASCE Structural Engineering Journal, Vol. 134, pp: 1310-1321.

9. Barros J.A.O., Costa I. G., Ventura-Gouveia A., 2011, "CFRP flexural and shear strengthening technique for RC beams: experimental and numerical research", Journal of Advances in Structural Engineering, Vol. 14, pp: 559-581.

10. José Sena-Cruz, 2004, "Strengthening of concrete structures with near-surface mounted CFRP laminate strips", PhD thesis, Minho University, Portugal.

11. Selcom multiaxial technology company, Biaxial products. http://www.multiaxialfabricselcom.com/en/Products/

12. Ventura-Gouveia A., Barros J.A.O., Azevedo A.F.M., 2011, "Crack constitutive model for the prediction of punching failure modes of fiber reinforced concrete laminar structures", Journal of Computers and Concrete, Vol. 8, pp: 735-755.

13. BS EN 1992-1-1:2004 Eurocode 2: Design of concrete structures - Part 1.1: General rules and rules for buildings; with UK National Annex to BS EN 1992-1-1:2004.

14. Bank L.C., 2006, "Composites for construction: Structural design with FRP materials", John Wiley \& Sons, New Jersey, pp: 413.

Mastali, Mohammad, Valente, Isabel B., Barros, Joaquim A. O. (2016).

Development of innovative hybrid sandwich panel slabs: Advanced numerical simulations and parametric studies.

Paper submitted to Composite Structures, Elsevier, ISSN 0263-8223. 
15. Mastali M., Valente I.B., Barros J.O.A., 2013, "New composite slab system for the structural rehabilitation of traditional buildings", FRPRCS11, Guimaraes, Portugal.

16. Eurocomp, 1996, "Structural Design of Polymer Composites", Eurocomp Design Code and Handbook (J. Clarke, ed.), E\&FN Spon, London, UK.

17. Khoramishad H., Crocombe A.D., Katnam K.B., Ashcroft I.A., 2010, "Predicting fatigue damage in adhesively bonded joints using a cohesive zone model", International Journal of Fatigue, Vol. 32, pp:1146-1158.

18. Corigliano A., Allix O., 2000, "Some aspects of interlaminar degradation in composites", Journal of Computer Methods Application Mechanic Engineering, Vol. 185, pp: 203-224.

19. Taleb Obaidat Y., Susanne H., Dahlblom O., 2010, "The effect of CFRP and CFRP/concrete interface models when modelling retrofitted RC beams with FEM", Journal of Composite Structures, Vol. 92, pp: 1391-1398.

20. Qiao P., Chen Y., 2008, "Cohesive fracture simulation and failure modes of FRP-concrete bonded interfaces", Journal of Theoretical and Applied Fracture Mechanics, Vol. 49, pp: 213-225.

21. Lameiras R., Barros J.A.O., Valente I.B., Azenha M., 2013, "Development of sandwich panels combining fiber reinforced concrete layers and fiber reinforced polymer connectors. Part I: Conception and pull-out tests", Journal of Composite Structures, Vol. 105, pp: 446459.

22. Langdon D., 2014, “Spon’s Architects' and Builders' Price Book”, CRC Press, UK.

23. Kollar L.P., 2003, "Mechanics of composite structures", Cambridge University Press, Cambridge, UK.

24. Lorenzis L., Fernandob D., Teng J., 2013, “Coupled mixed-mode cohesive zone modeling of interfacial debonding in simply supported plated beams", International Journal of Solids and Structures, Vol. 50, pp: 2477-2494.

Mastali, Mohammad, Valente, Isabel B., Barros, Joaquim A. O. (2016).

Development of innovative hybrid sandwich panel slabs: Advanced numerical simulations and parametric studies.

Paper submitted to Composite Structures, Elsevier, ISSN 0263-8223. 
25. Elices M., Guinea G.V., Gómez J., Planas J., 2002, "The cohesive zone model: advantages, limitations and challenges", Journal of Engineering Fracture Mechanics, Vol. 69, pp: 137-163.

26. Jin Z.H., Sun C.T., 2006, "A comparison of cohesive zone modeling and classical fracture mechanics based on near tip stress field", International Journal of Solids and Structures, Vol. 43, pp: 1047-1060.

27. Faella C., Martinelli E., Nigro E., 2010, "Steel-concrete composite beams in partial interaction: Closed-form "exact" expression of the stiffness matrix and the vector of equivalent nodal forces", Journal of Engineering Structures, Vol. 32, pp: 2744-2754.

28. Ventura-Gouveia A., 2011, "Constitutive models for the material nonlinear analysis of concrete structures including time dependent effects", PhD Thesis, Dep. Civil Eng., Minho University, Portugal.

29. Web

link

of

GiD

manual: ftp://www.gidhome.com/pub/GiD Documentation/Docs/GiD 12 Reference Manual.pdf

30. Kmiecik P, Kaminski M., 2011, "Modeling of reinforced concrete structures and composite structures with concrete strength degradation taken into consideration", Archives of civil and mechanical engineering, Wroclaw University of Technology, No.3, Poland.

Mastali, Mohammad, Valente, Isabel B., Barros, Joaquim A. O. (2016).

Development of innovative hybrid sandwich panel slabs: Advanced numerical simulations and parametric studies.

Paper submitted to Composite Structures, Elsevier, ISSN 0263-8223. 


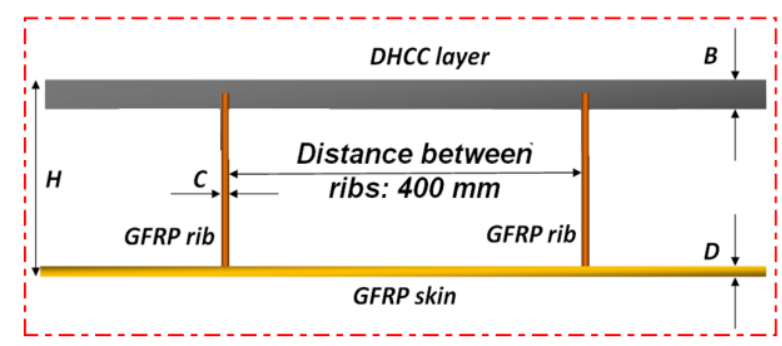

a) Cross section of the proposed sandwich panel

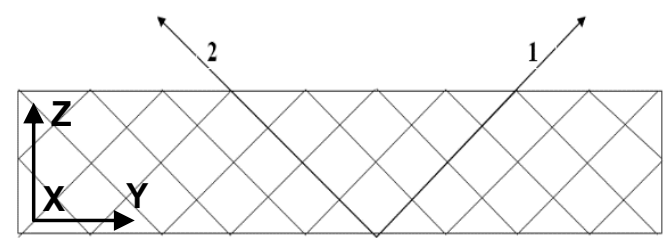

c) Ribs: fibers oriented at $\pm 45^{\circ}$

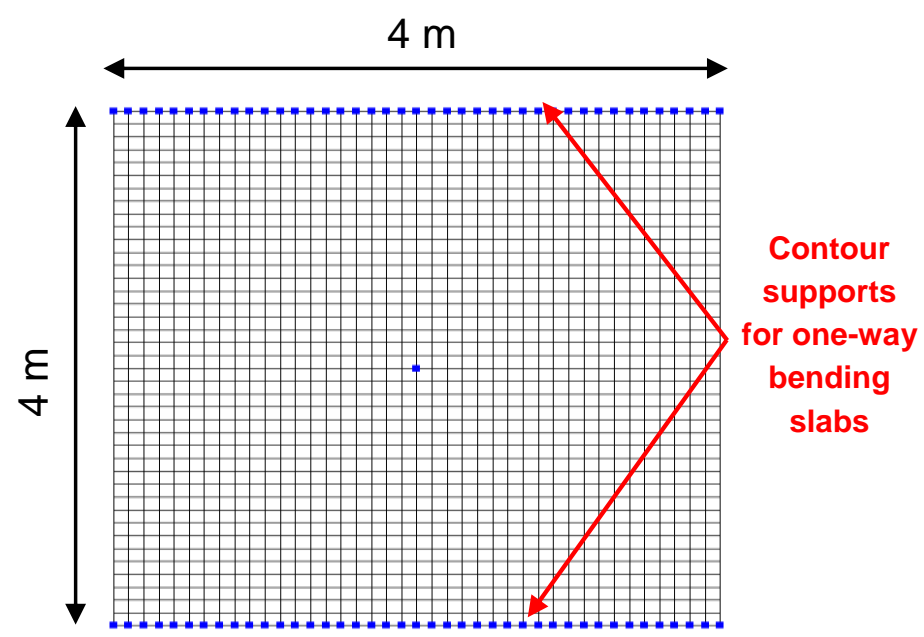

b) Slab plan and support conditions

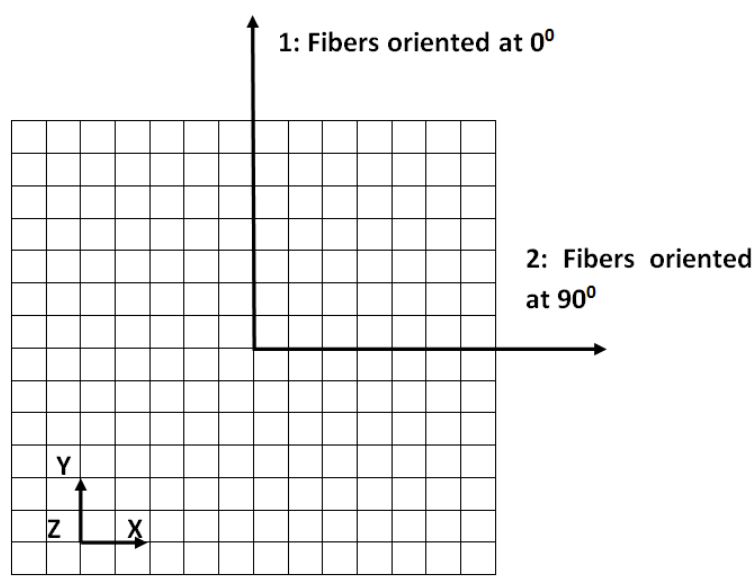

d) Skins: fibers oriented at $0^{\circ}$ and $90^{\circ}$

Fig 1. Schematic representations of the slab

Mastali, Mohammad, Valente, Isabel B., Barros, Joaquim A. O. (2016).

Development of innovative hybrid sandwich panel slabs: Advanced numerical simulations and parametric studies.

Paper submitted to Composite Structures, Elsevier, ISSN 0263-8223. 


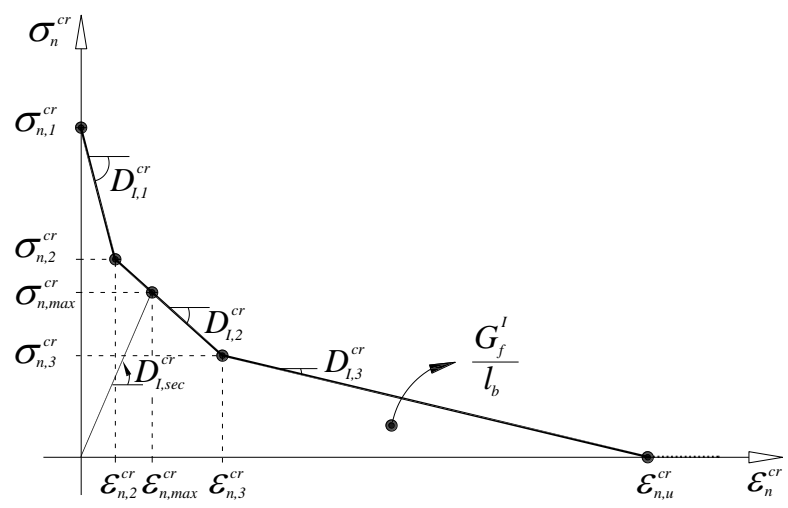

Fig. 2 Trilinear stress-strain diagram to simulate the fracture mode I crack propagation

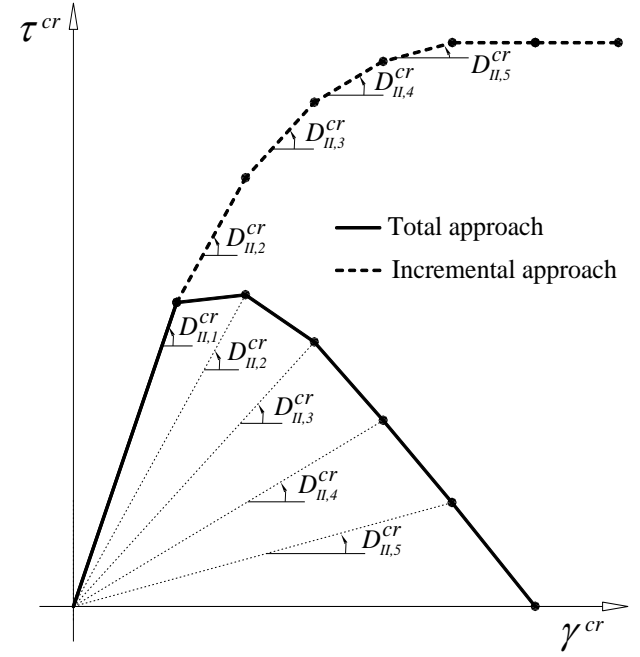

Fig. 3. Relation between crack shear stress and crack shear strain for the incremental and total approaches. 


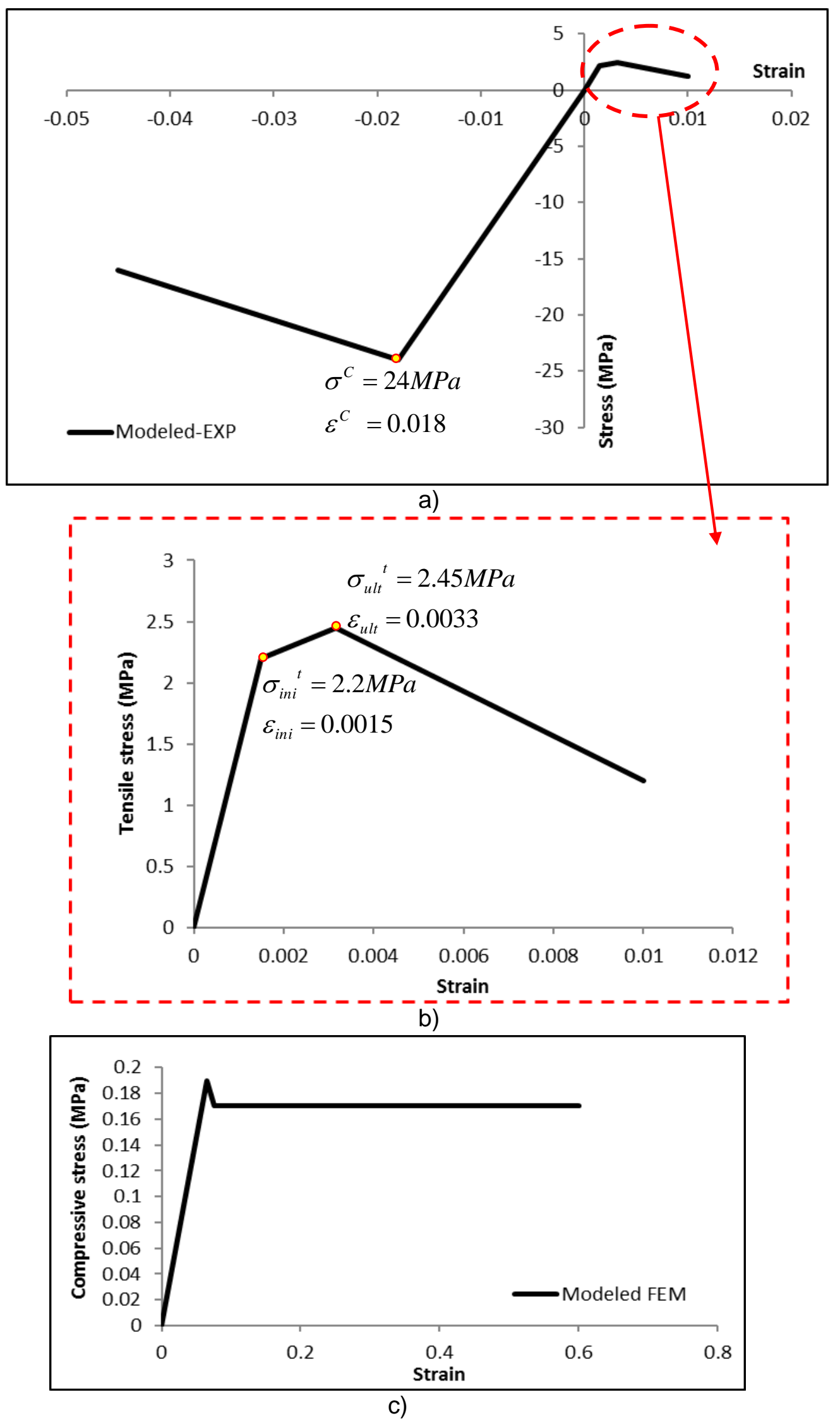

Fig 4. Stress-strain curves for FEM modeling: a) DHCC layer in both compression and tension; b) DHCC layer in compression; c) Foam core in compression

Mastali, Mohammad, Valente, Isabel B., Barros, Joaquim A. O. (2016).

Development of innovative hybrid sandwich panel slabs: Advanced numerical simulations and parametric studies.

Paper submitted to Composite Structures, Elsevier, ISSN 0263-8223. 


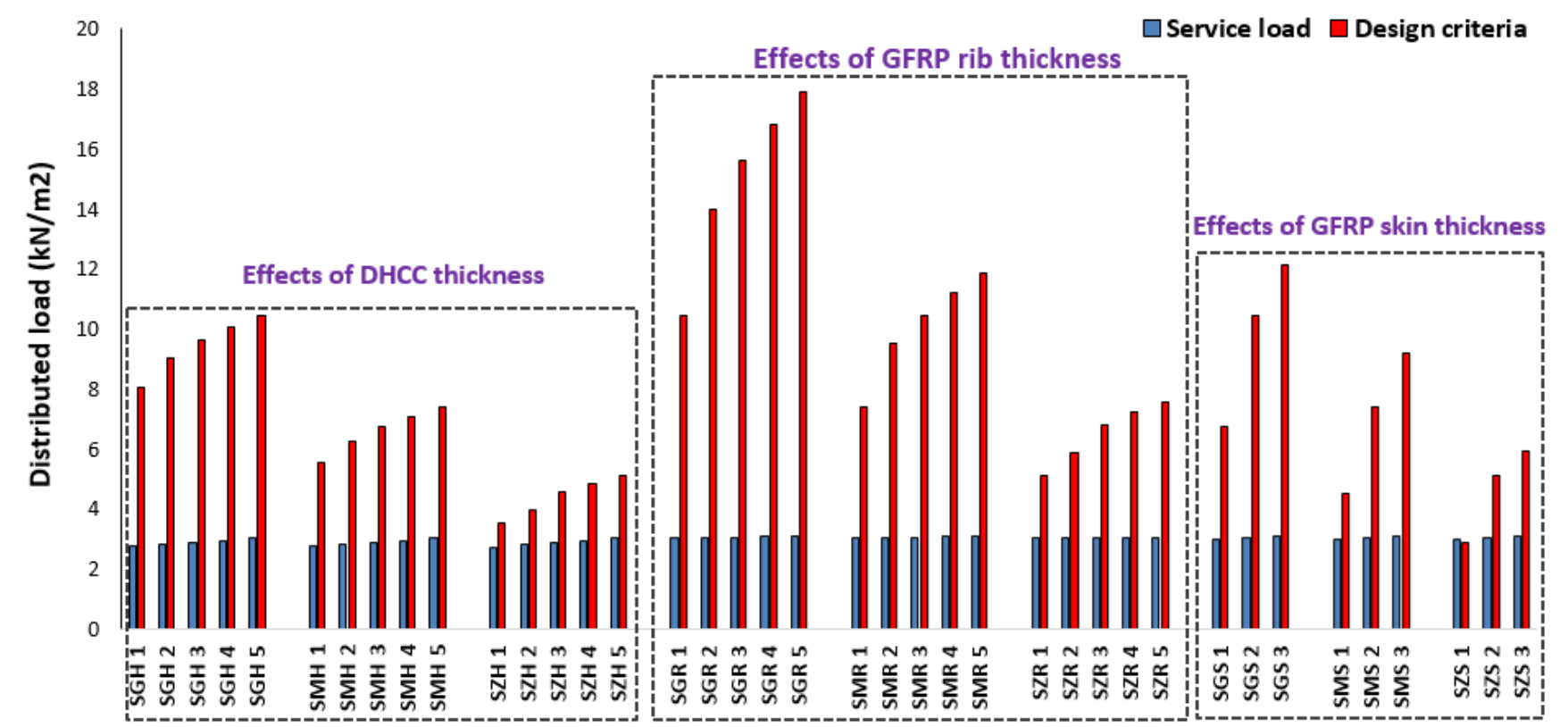

a)

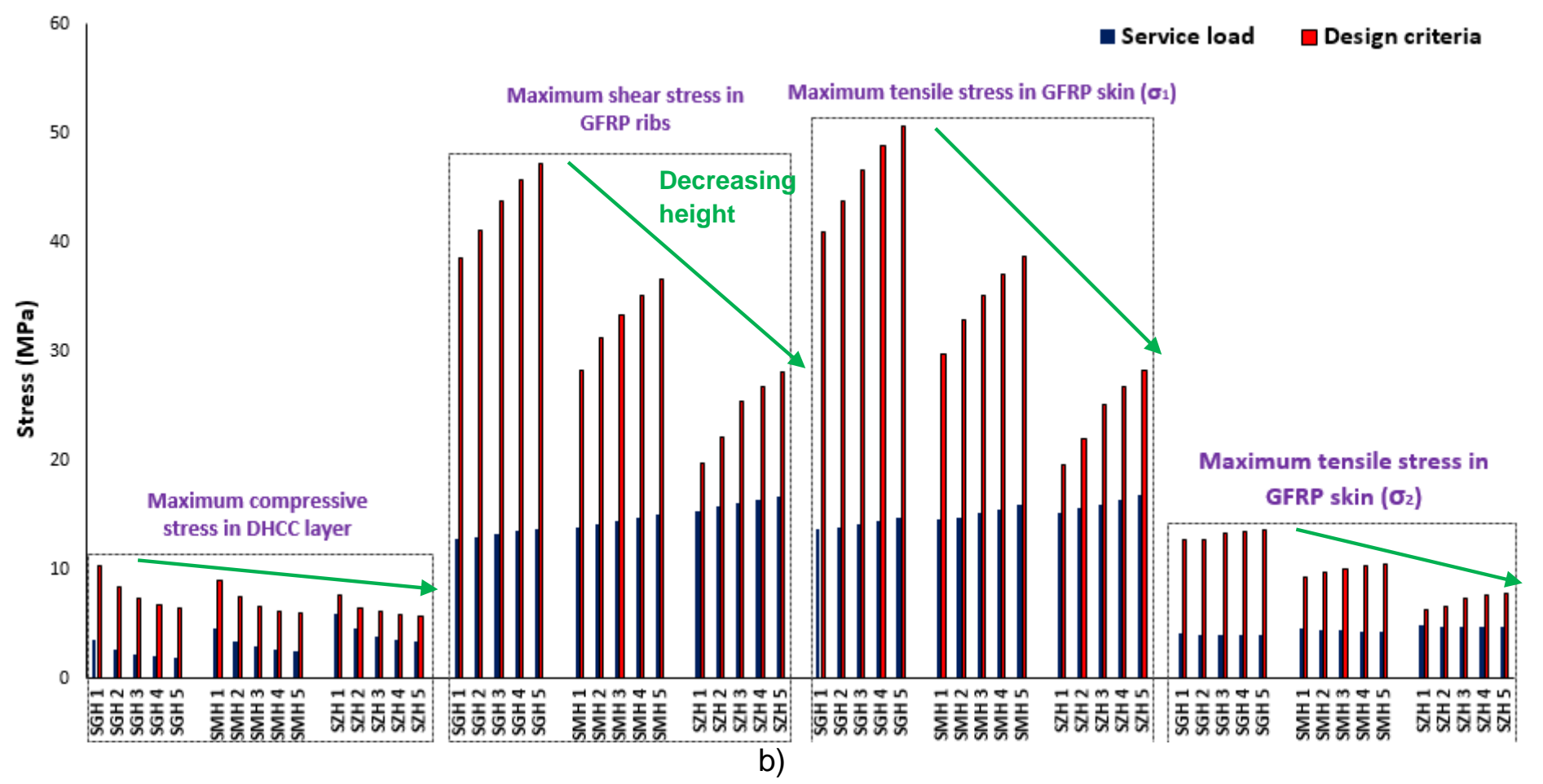

Mastali, Mohammad, Valente, Isabel B., Barros, Joaquim A. O. (2016).

Development of innovative hybrid sandwich panel slabs: Advanced numerical simulations and parametric studies.

Paper submitted to Composite Structures, Elsevier, ISSN 0263-8223. 


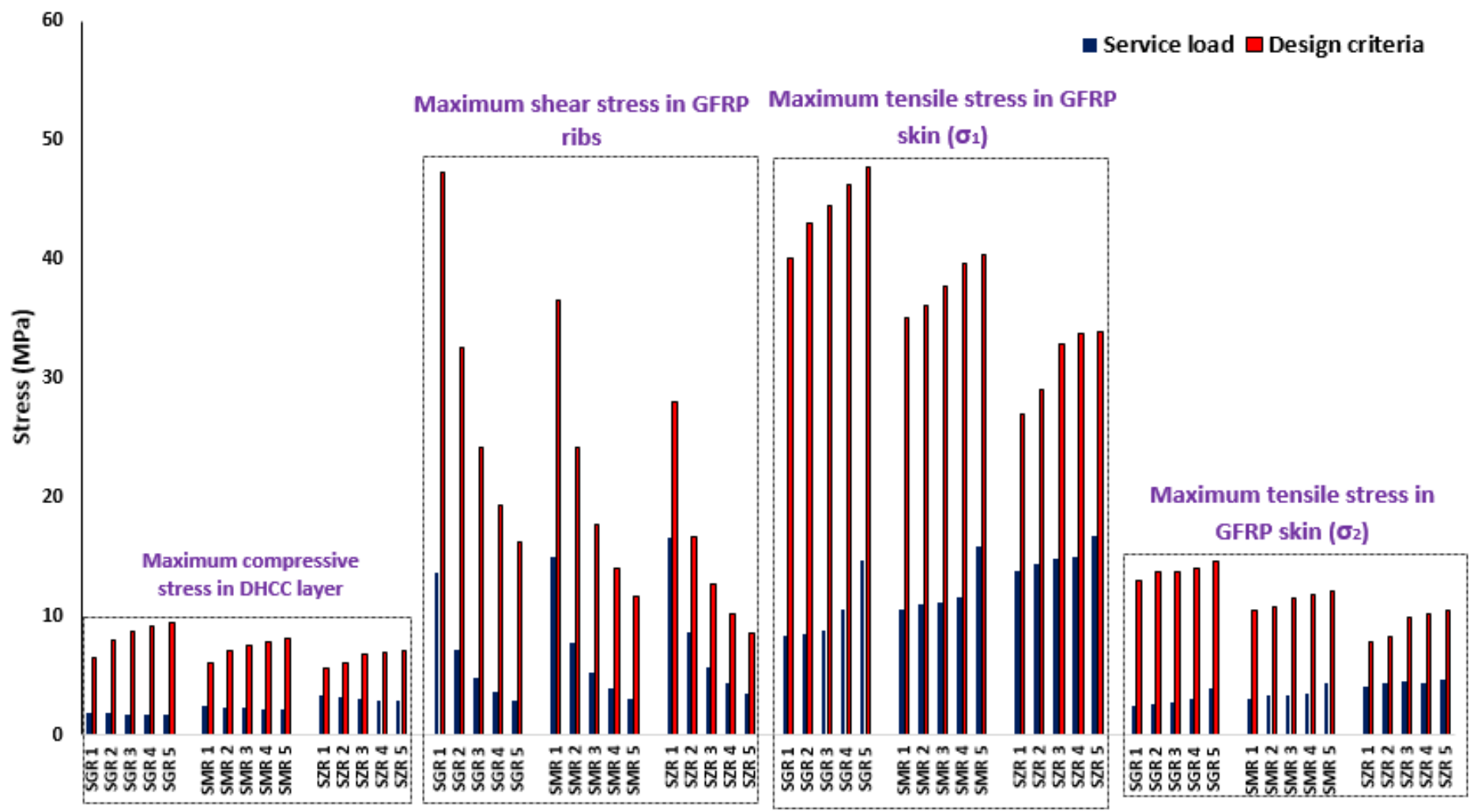

c)

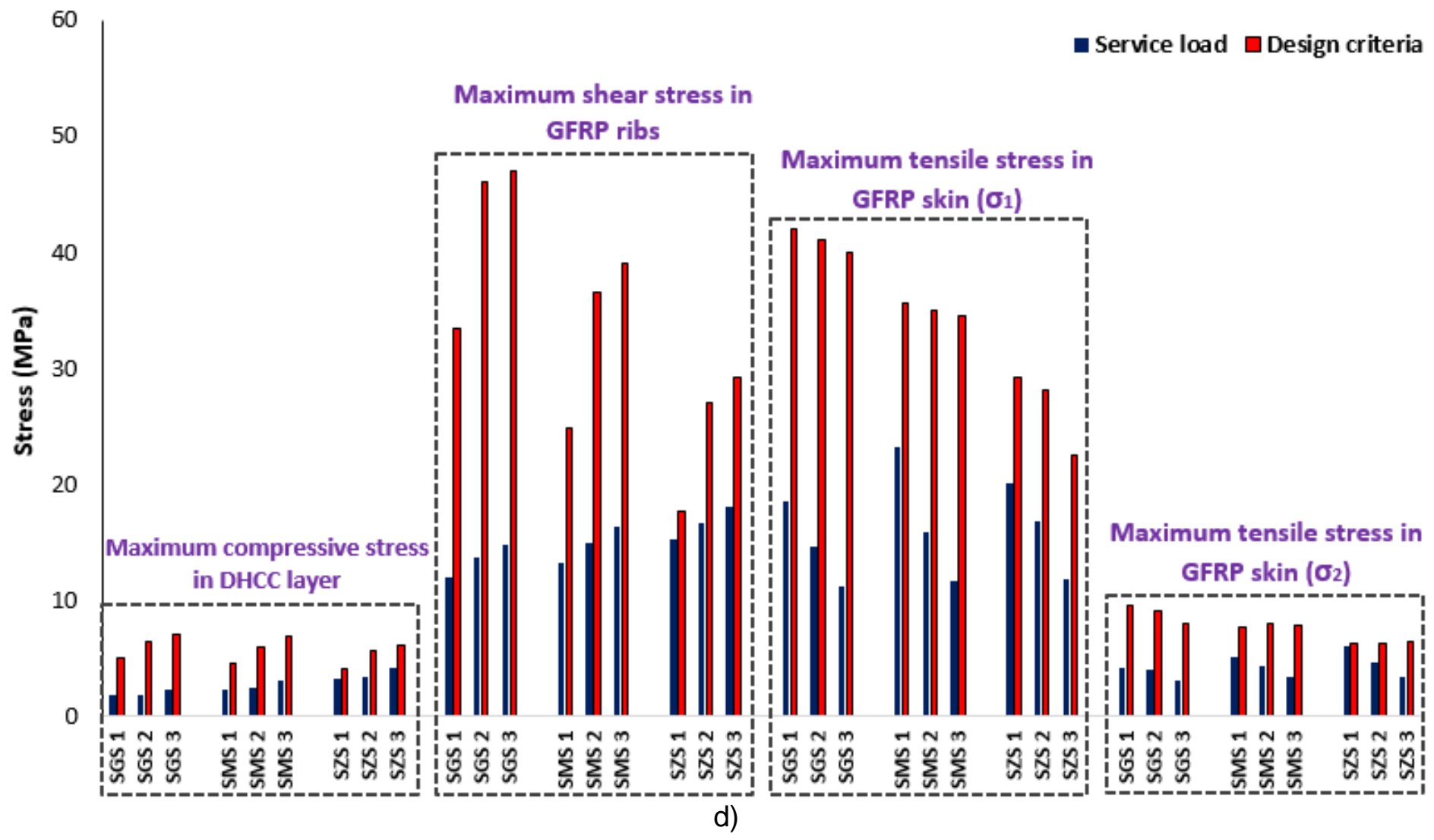

Mastali, Mohammad, Valente, Isabel B., Barros, Joaquim A. O. (2016).

Development of innovative hybrid sandwich panel slabs: Advanced numerical simulations and parametric studies.

Paper submitted to Composite Structures, Elsevier, ISSN 0263-8223. 


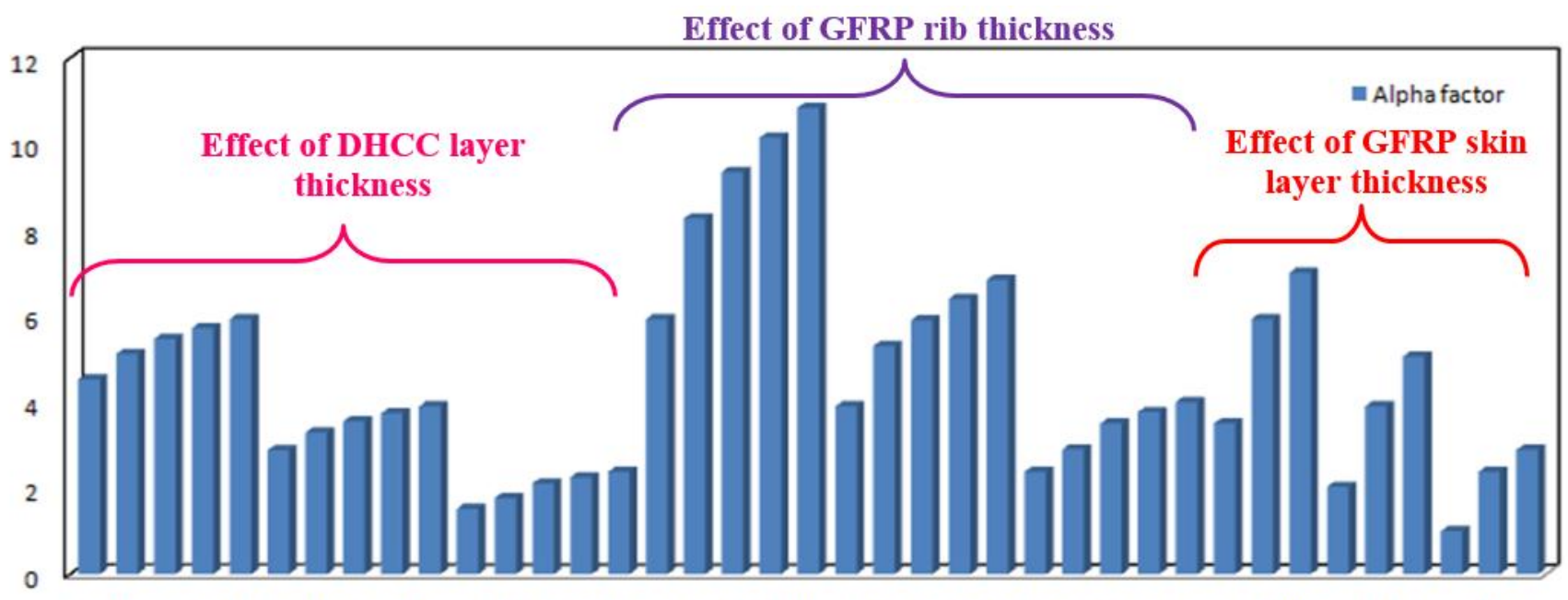

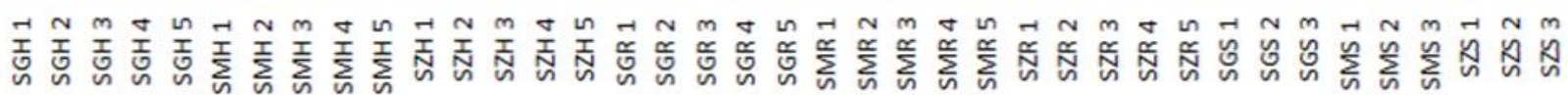

e)

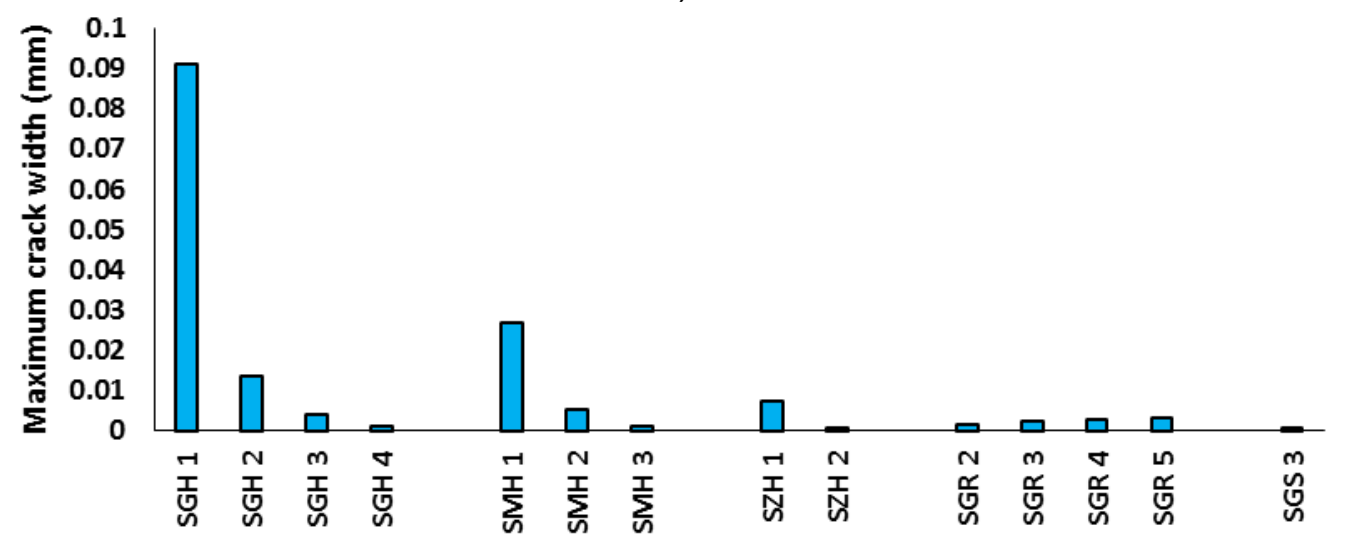

f)

Fig 5. a) Effects of increasing slab's components on distributed load; b) Effects of increasing DHCC layer on stress fields; c) Effects of increasing GFRP ribs on the stress fields; d) Effects of increasing GFRP skin on the stress fields; e) Effects of increasing slab's components on a factor; f) The recorded maximum crack width 


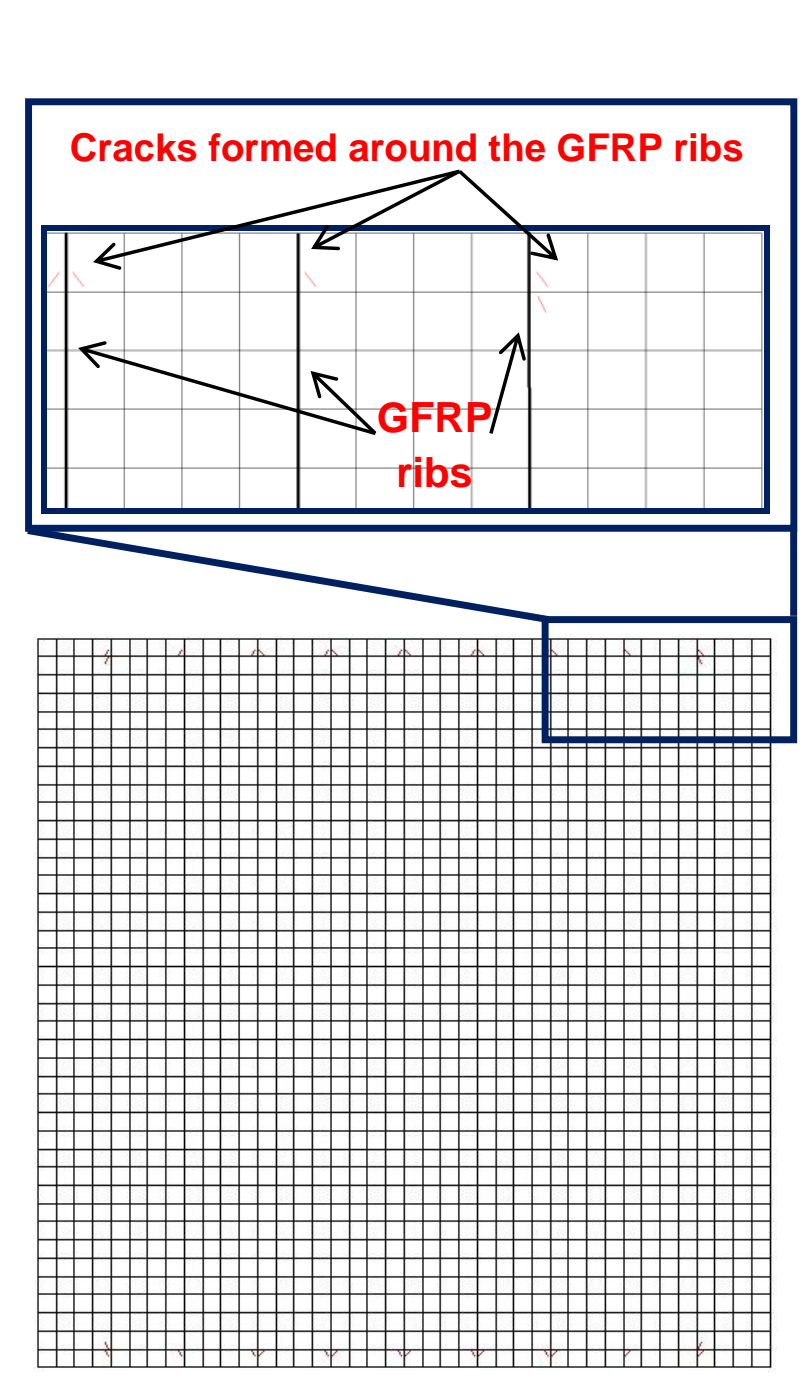

a)

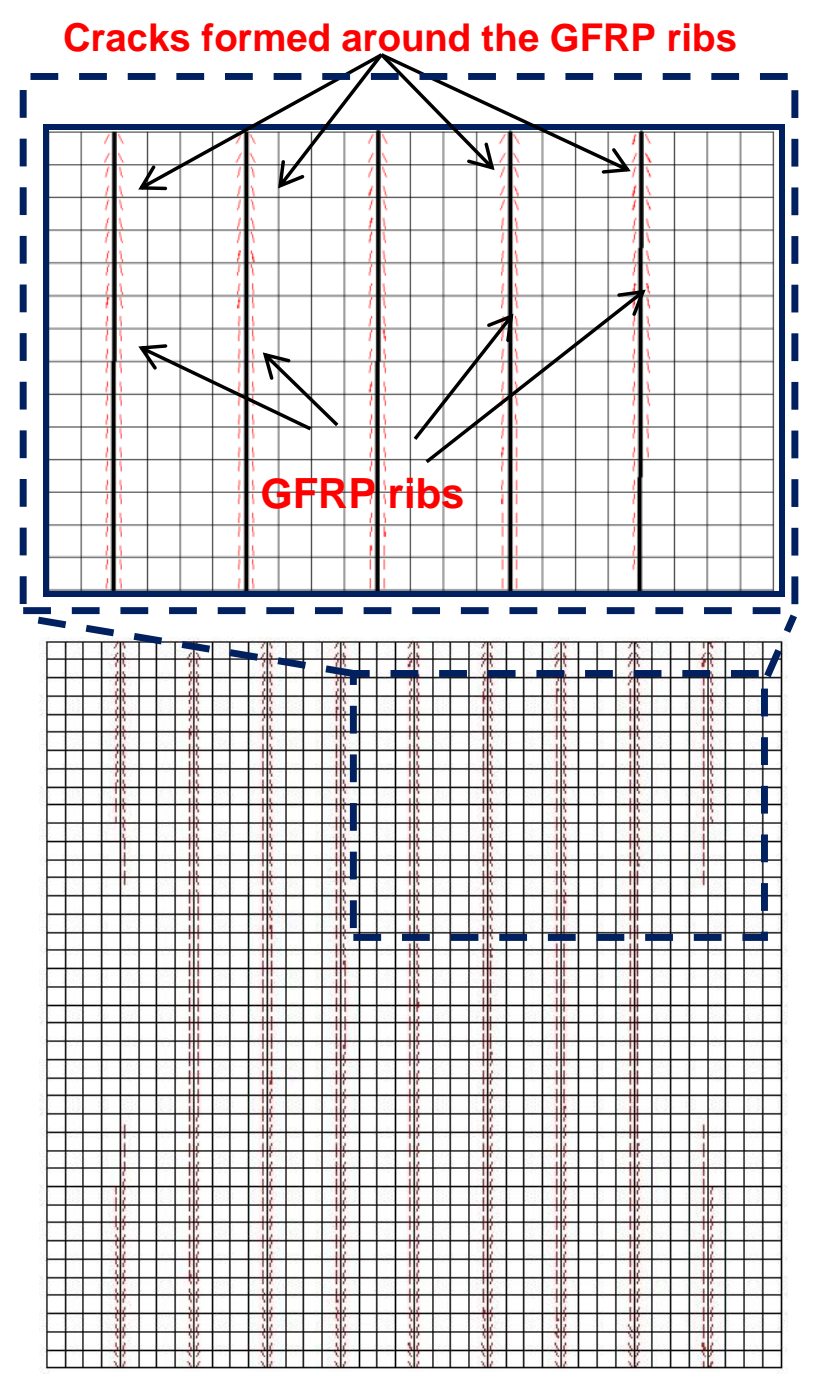

b)

Fig 6. Crack patterns in DHCC layer: a) with $25 \mathrm{~mm}$ thickness (SGH4); b) with $10 \mathrm{~mm}$ thickness (SGH1)

Mastali, Mohammad, Valente, Isabel B., Barros, Joaquim A. O. (2016).

Development of innovative hybrid sandwich panel slabs: Advanced numerical simulations and parametric studies.

Paper submitted to Composite Structures, Elsevier, ISSN 0263-8223. 


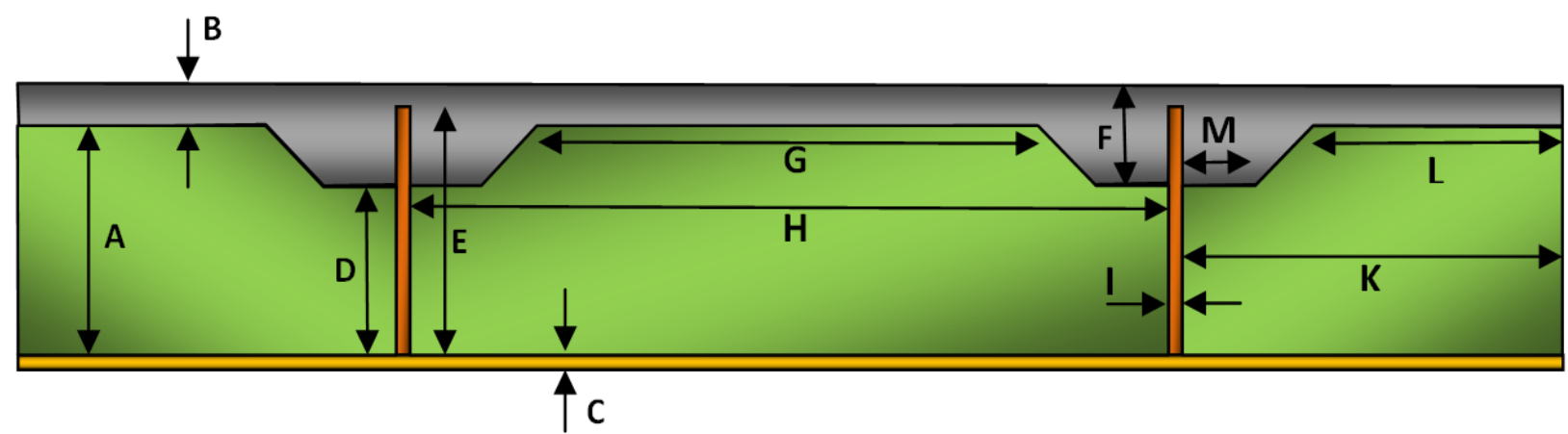

Fig 7. Dimensions of the proposed hybrid slab's components

Mastali, Mohammad, Valente, Isabel B., Barros, Joaquim A. O. (2016).

Development of innovative hybrid sandwich panel slabs: Advanced numerical simulations and parametric studies.

Paper submitted to Composite Structures, Elsevier, ISSN 0263-8223. 

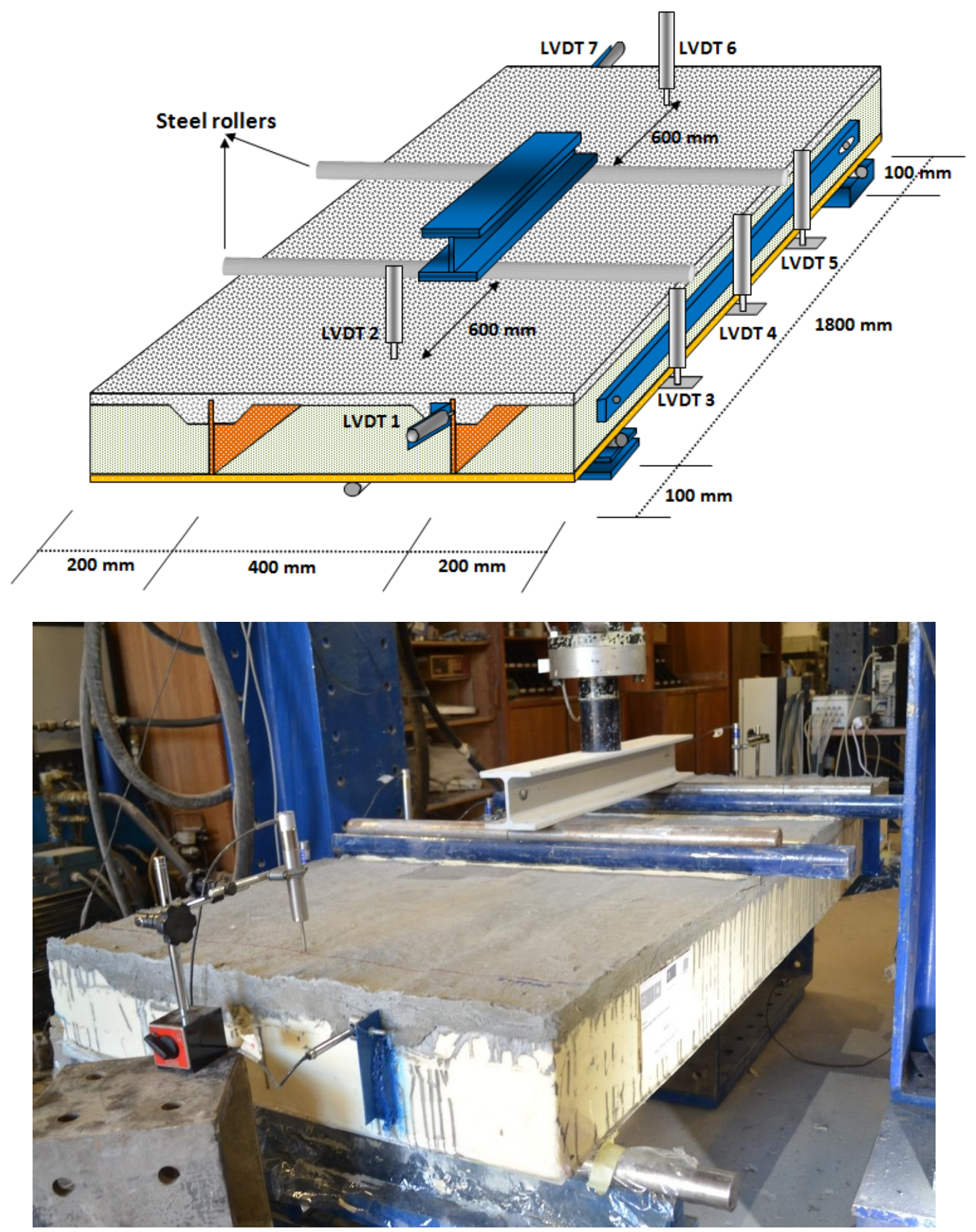

Fig 8. Schematic figure of the tested hybrid sandwich panels [5]

Mastali, Mohammad, Valente, Isabel B., Barros, Joaquim A. O. (2016).

Development of innovative hybrid sandwich panel slabs: Advanced numerical simulations and parametric studies.

Paper submitted to Composite Structures, Elsevier, ISSN 0263-8223. 


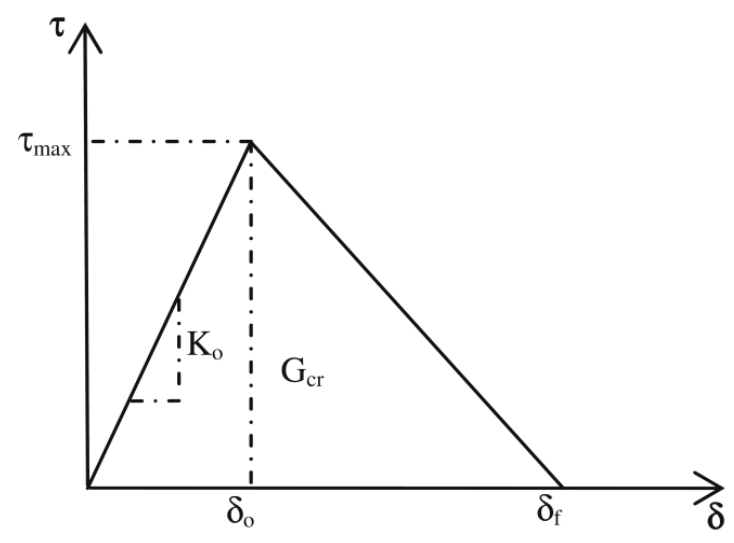

a)

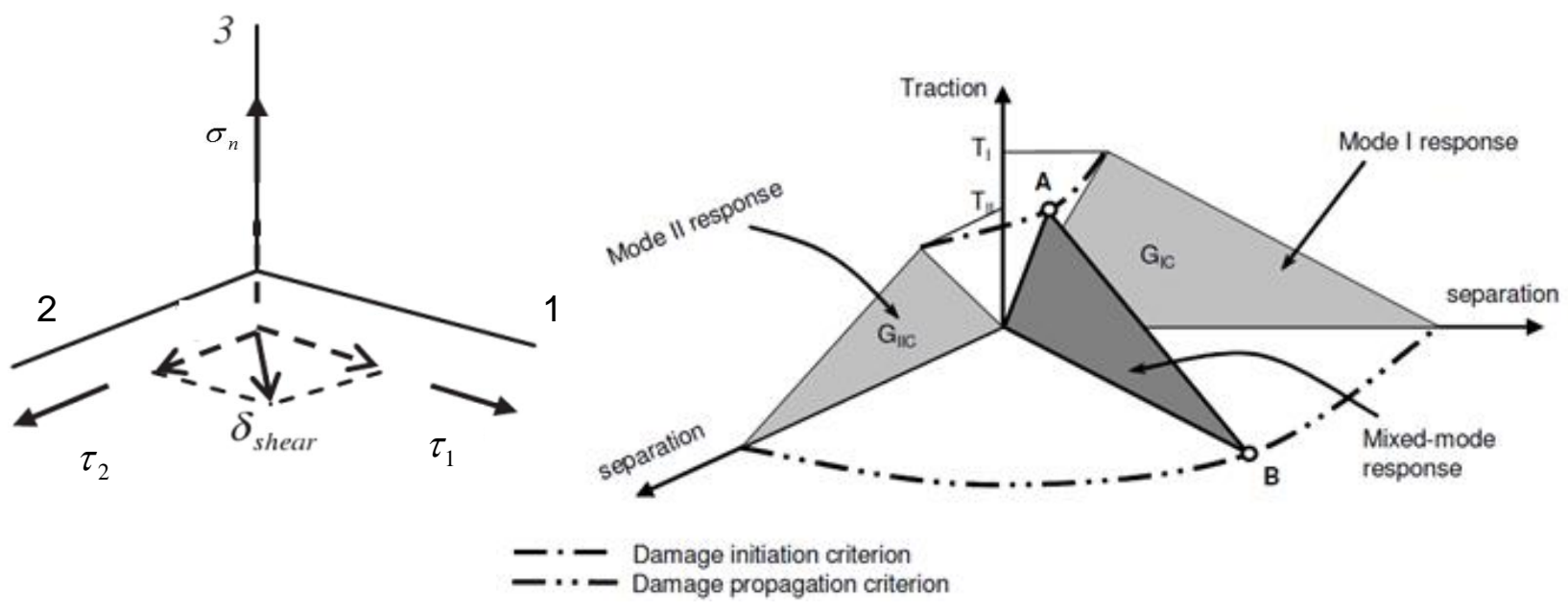

b)
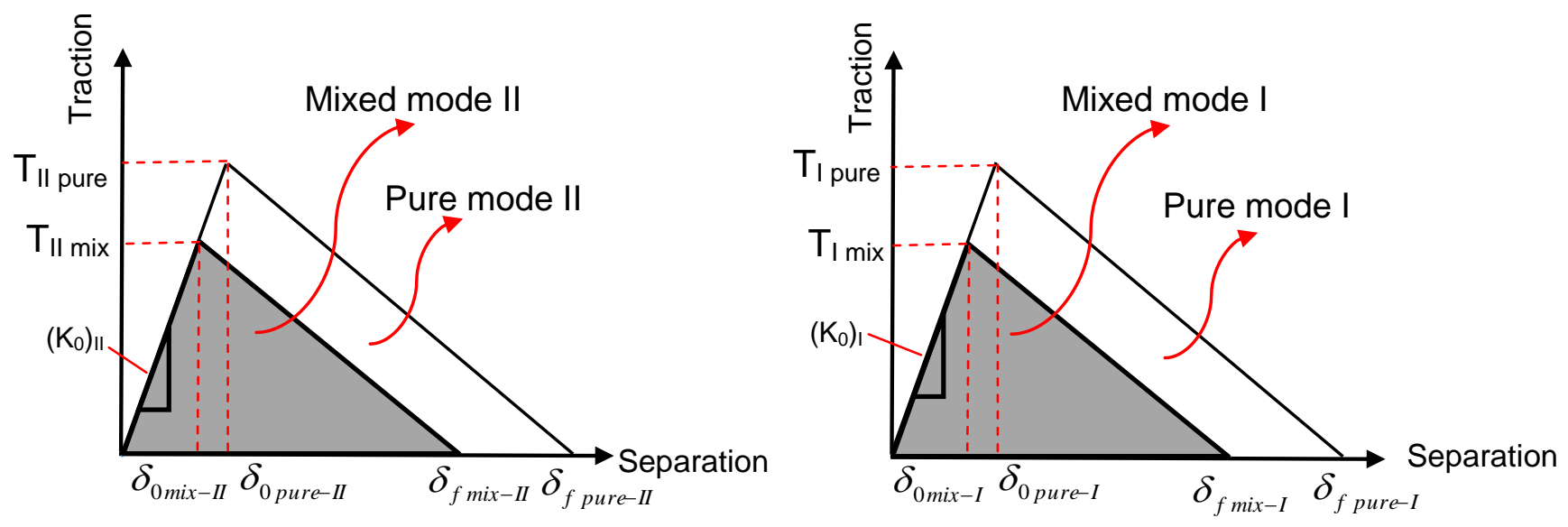

c)

Fig 9. a) Bilinear traction-separation constitutive law [6]; b) Mixed-mode bi-linear tractionseparation law [17]; Triangular model of mixed-mode bi-linear traction-separation law [24]

Mastali, Mohammad, Valente, Isabel B., Barros, Joaquim A. O. (2016).

Development of innovative hybrid sandwich panel slabs: Advanced numerical simulations and parametric studies.

Paper submitted to Composite Structures, Elsevier, ISSN 0263-8223. 


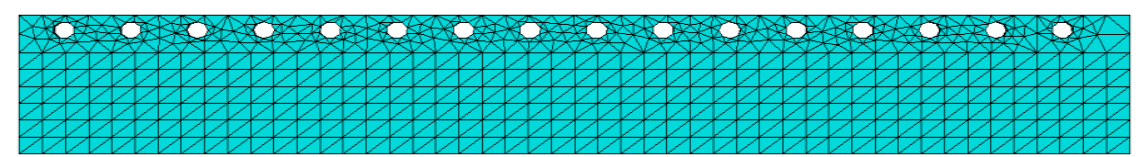

a) GFRP rib mesh

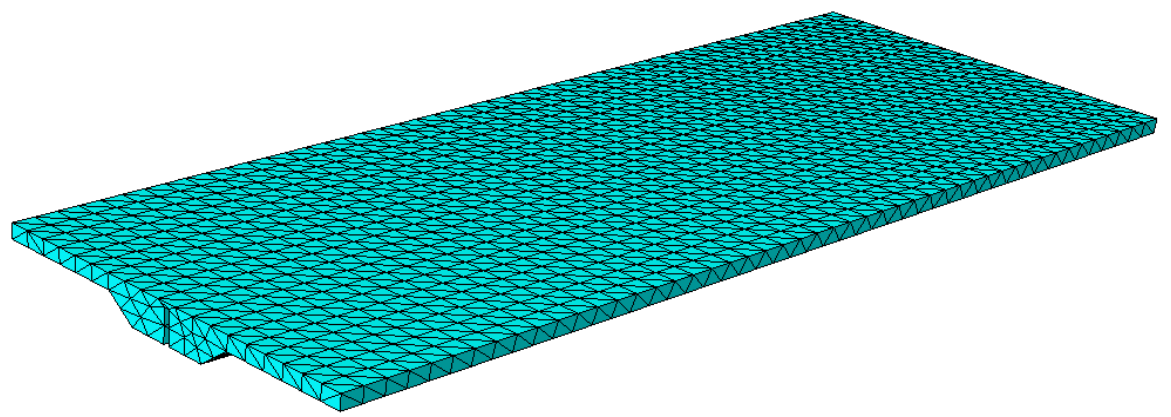

b) DHCC layer mesh

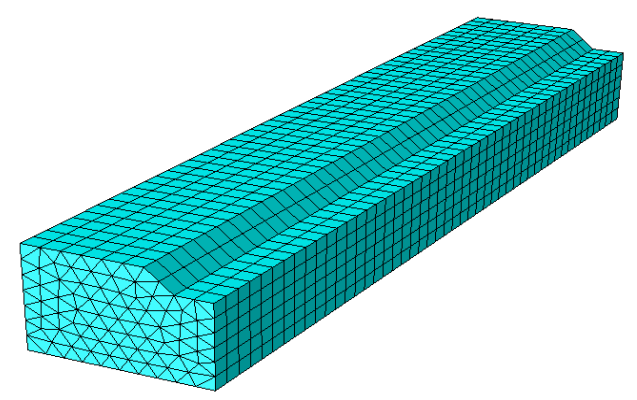

c) Foam core mesh

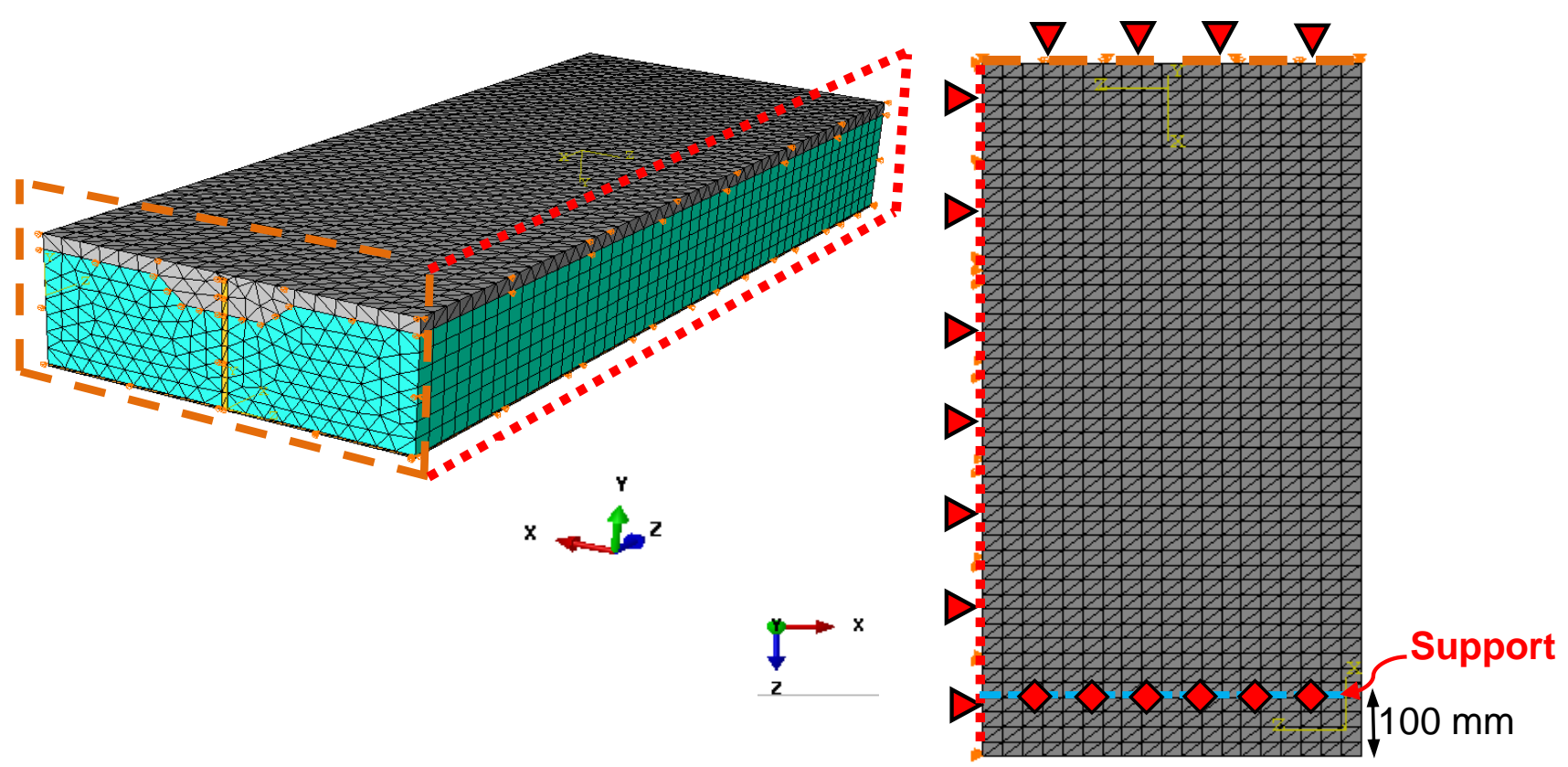

d) Boundary conditions

Fig 10. FE model of one quarter of the slab

Mastali, Mohammad, Valente, Isabel B., Barros, Joaquim A. O. (2016).

Development of innovative hybrid sandwich panel slabs: Advanced numerical simulations and parametric studies.

Paper submitted to Composite Structures, Elsevier, ISSN 0263-8223. 


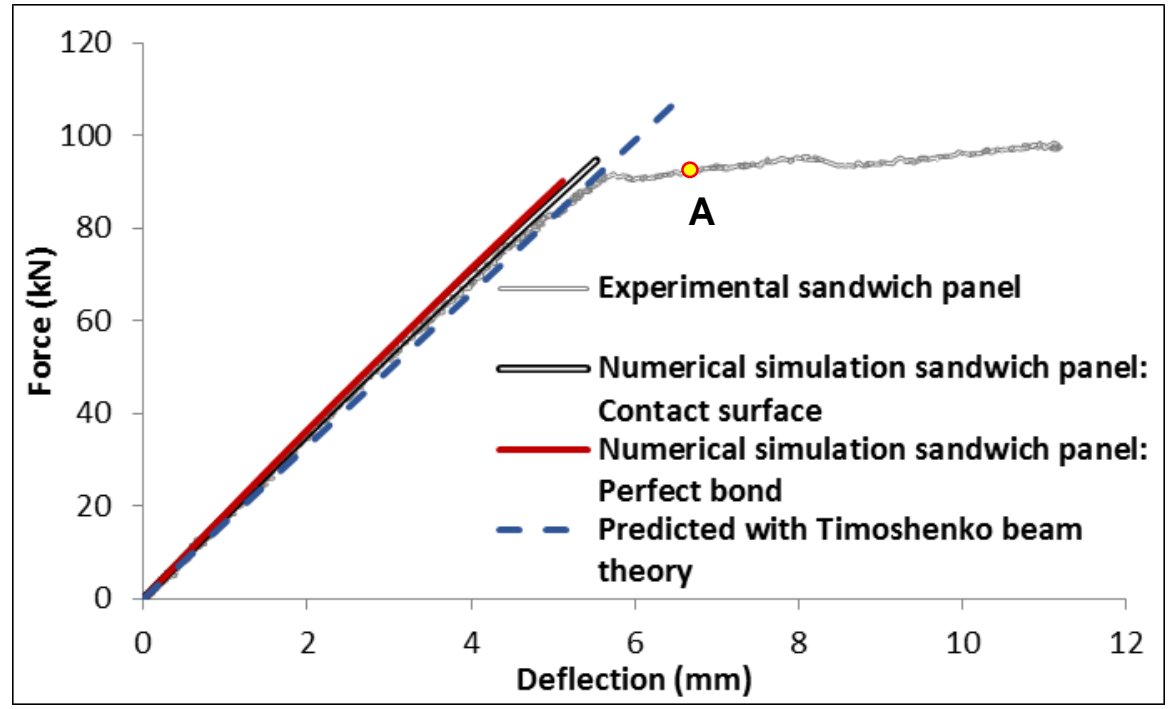

a) Slab 1

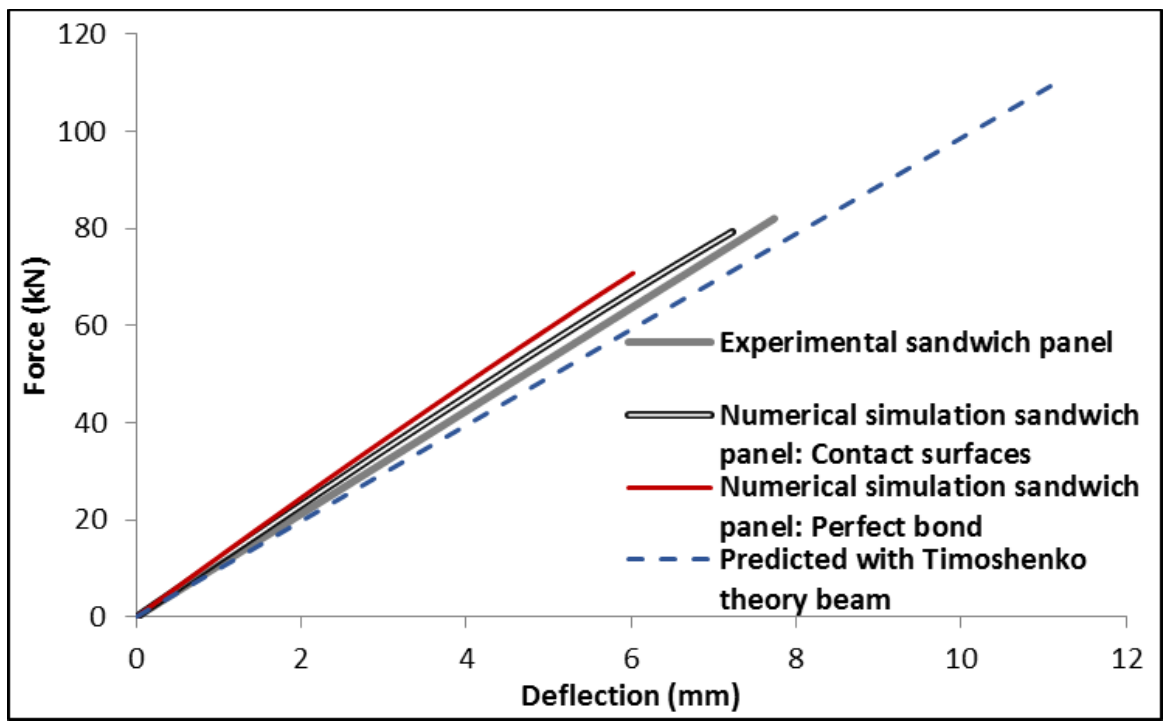

b) Slab 2

Fig 11. Comparison between experimental and numerical results

Mastali, Mohammad, Valente, Isabel B., Barros, Joaquim A. O. (2016).

Development of innovative hybrid sandwich panel slabs: Advanced numerical simulations and parametric studies.

Paper submitted to Composite Structures, Elsevier, ISSN 0263-8223. 


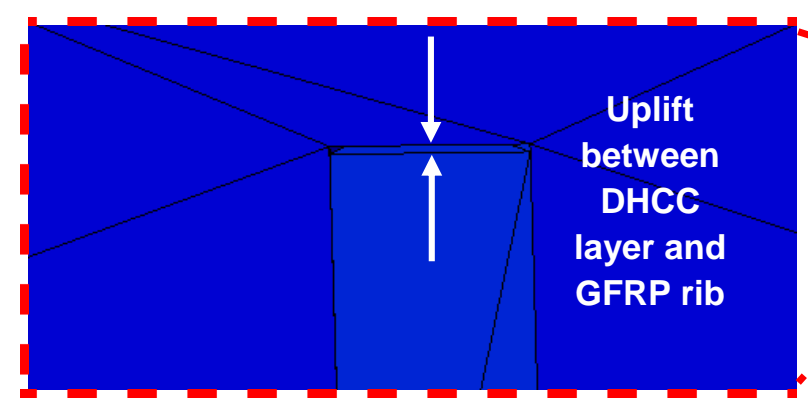

a)

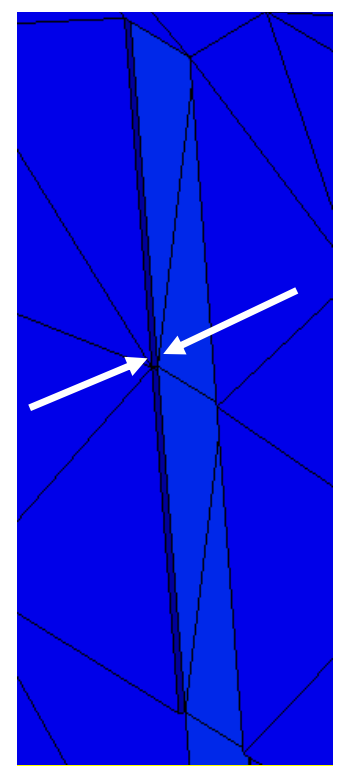

c)

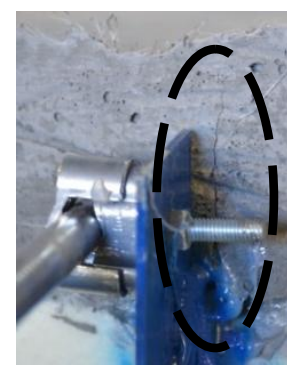

e)

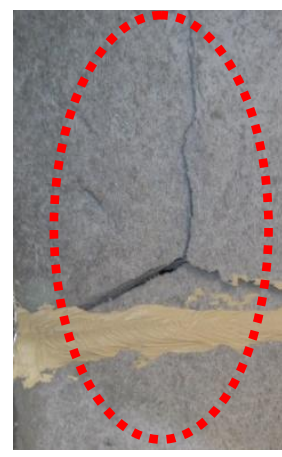

f)

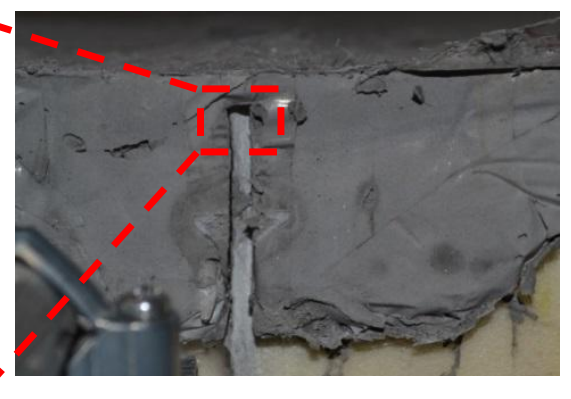

b)

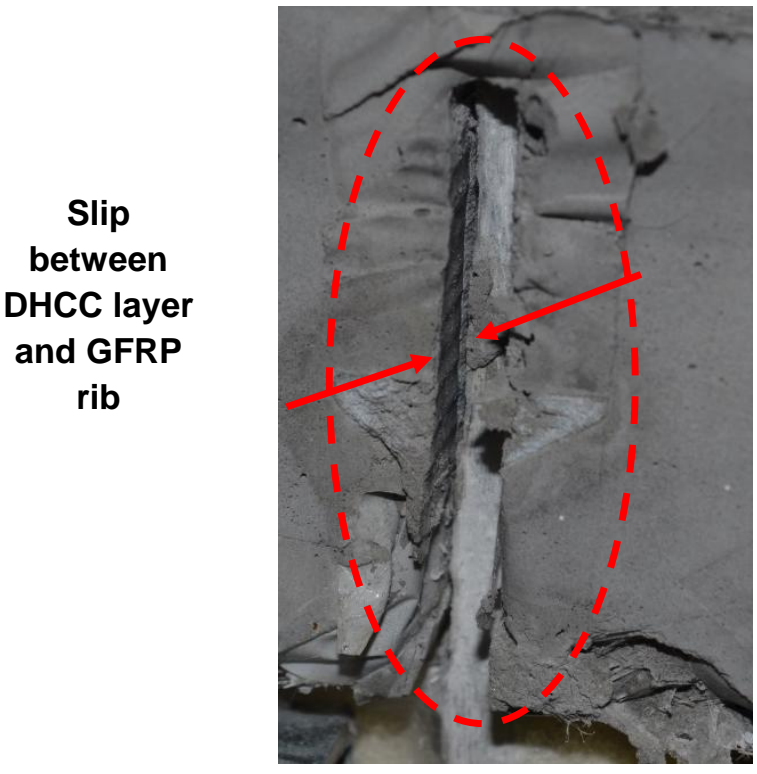

d)

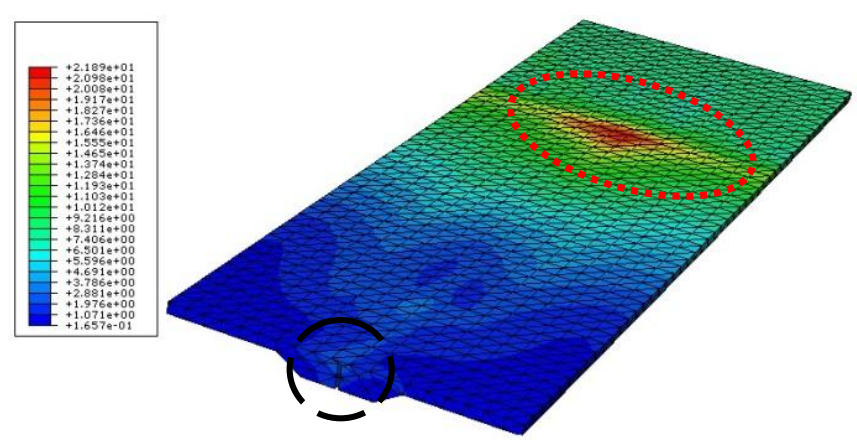

g)

Fig 12. Slab 2 - Separation between DHCC layer and GFRP rib: a) Uplift in the numerical model and b) Uplift in the experimental tests; c) Slip in the numerical model and d) Slip in the experimental tests; e) Formed crack in the connection zone between DHCC layer and GFRP rib; f) Localized compression in the DHCC layer; g) Von Mises stresses in the DHCC layer 


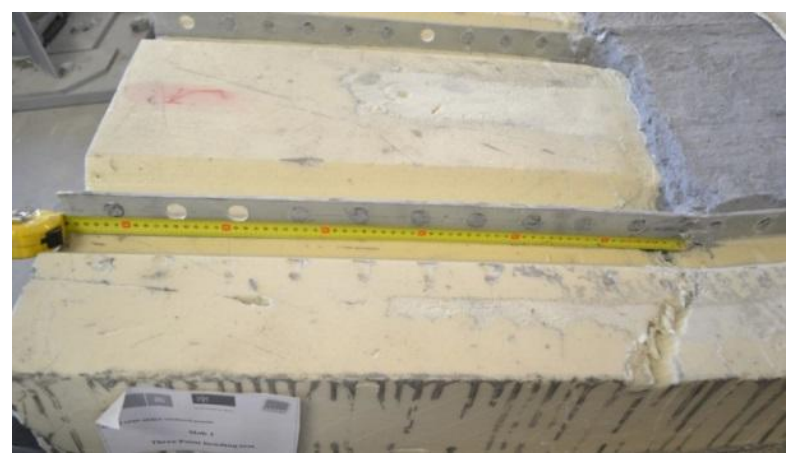

a) Damaged GFRP ribs after implementation of the experimental test in Slab 1

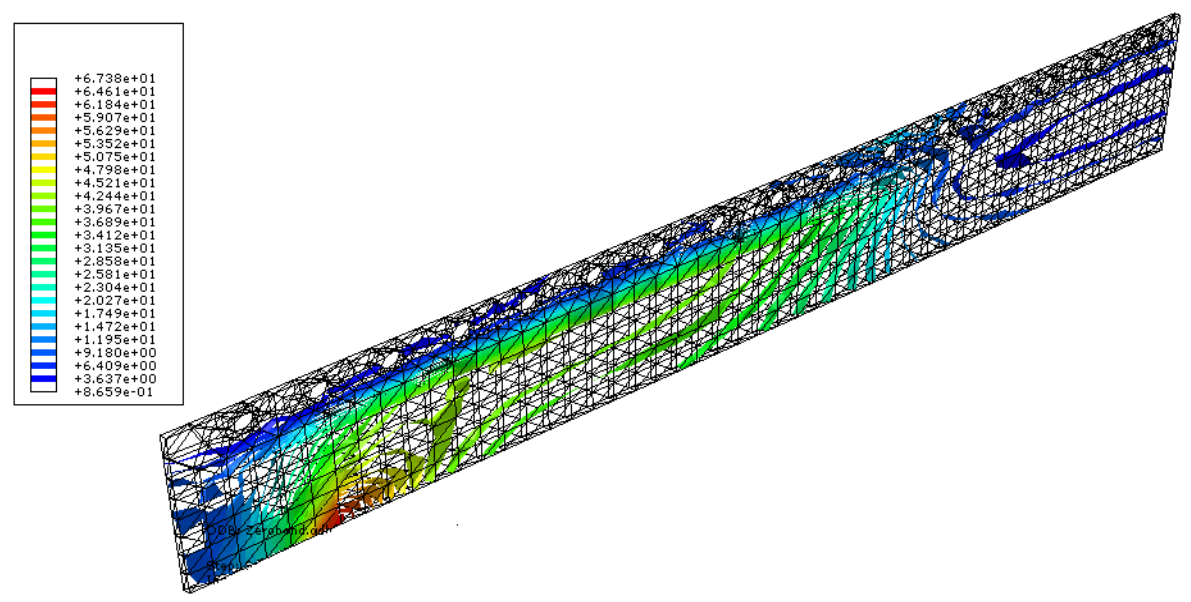

b) Distribution of longitudinal principal stresses in the GFRP rib of Slab 1

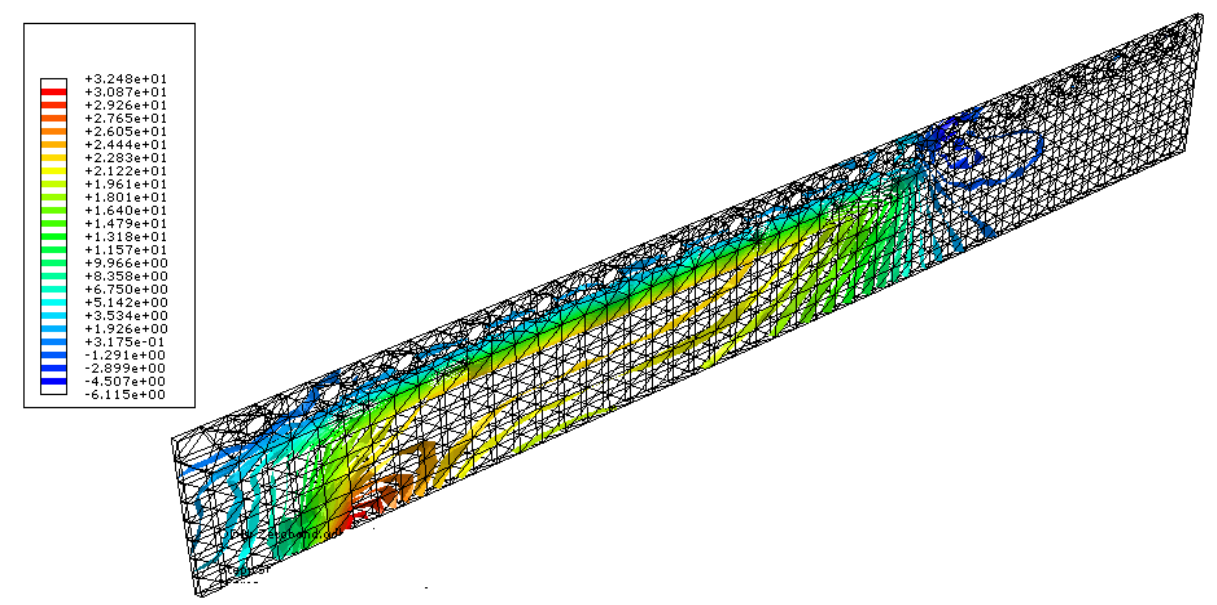

c) Distribution of shear stress in the GFRP rib of Slab 1

Mastali, Mohammad, Valente, Isabel B., Barros, Joaquim A. O. (2016).

Development of innovative hybrid sandwich panel slabs: Advanced numerical simulations and parametric studies.

Paper submitted to Composite Structures, Elsevier, ISSN 0263-8223. 

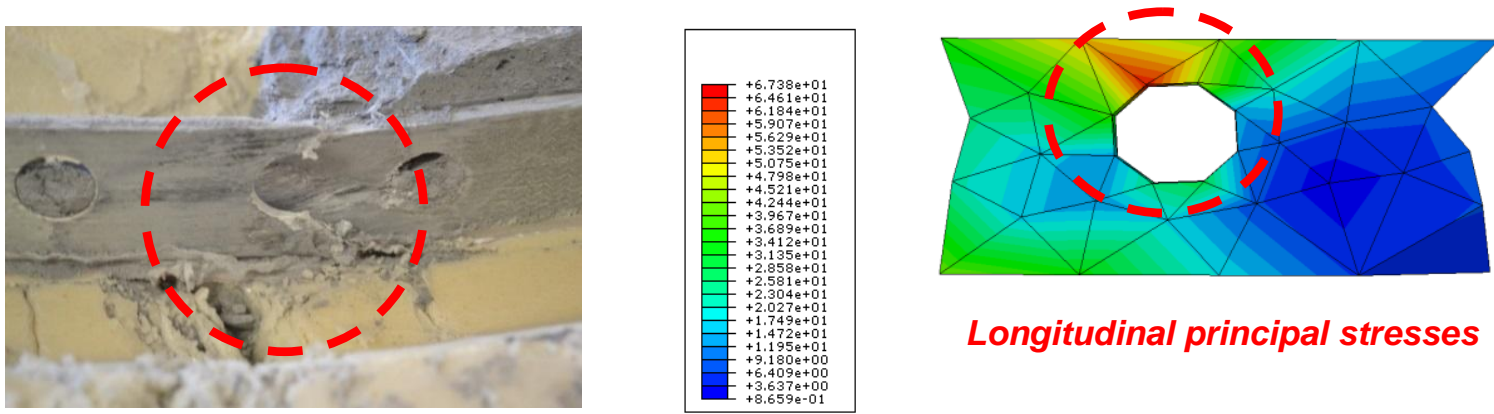

Longitudinal principal stresses

d) Experimental and numerical damage positions in the GFRP rib of Slab 1

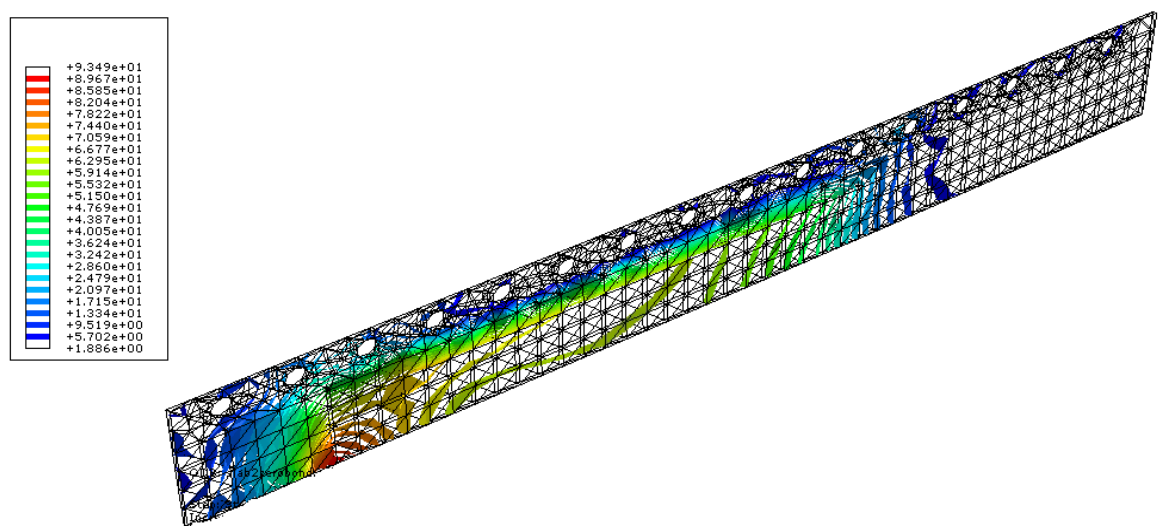

e) Distribution of longitudinal principal stresses in the GFRP rib of slab 2

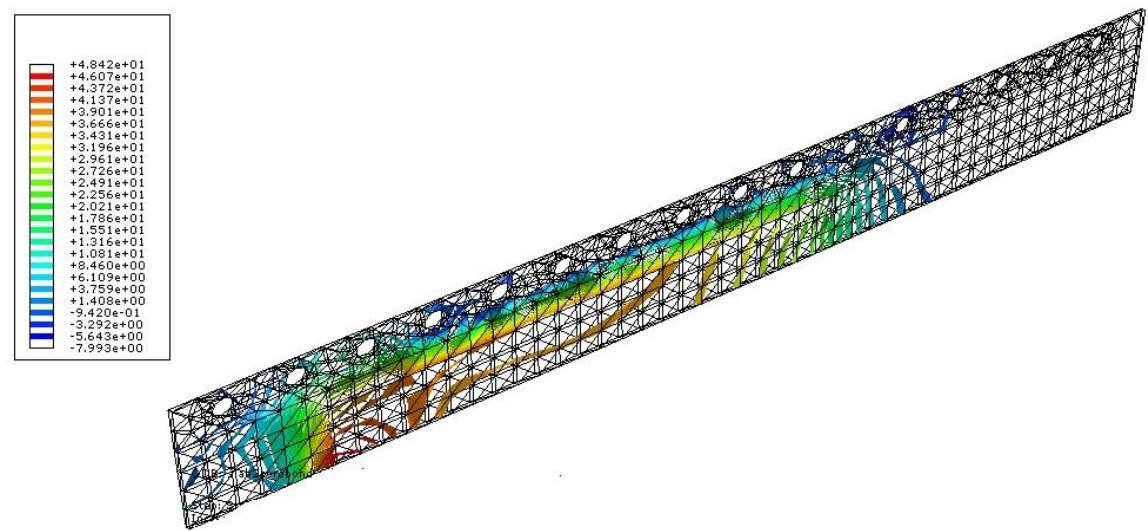

f) Distribution of shear stresses in the GFRP rib of Slab 2
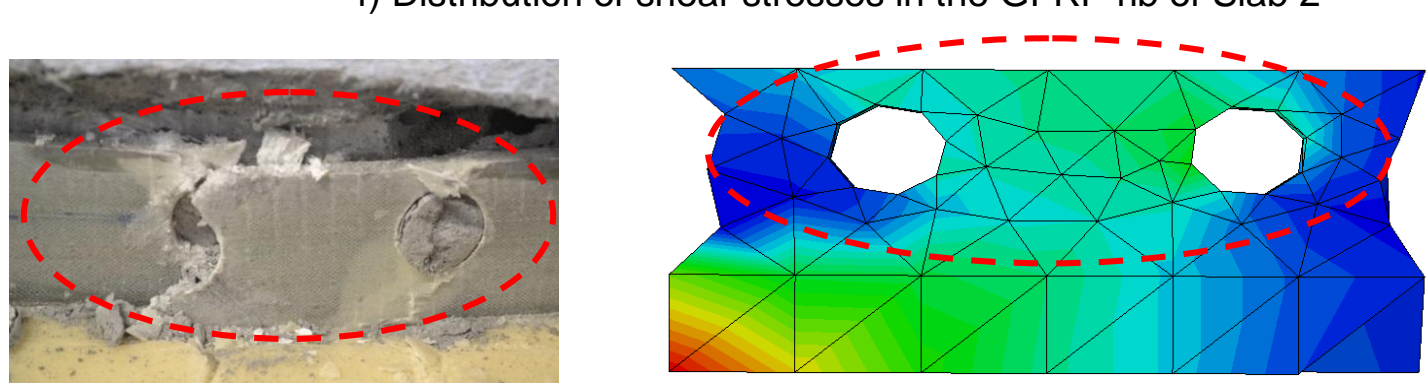

Longitudinal principal stresses

g) Numerical and experimental failure positions in the GFRP rib of Slab 2

Fig 13. Results obtained in the ribs of Slab1 and Slab 2

Mastali, Mohammad, Valente, Isabel B., Barros, Joaquim A. O. (2016).

Development of innovative hybrid sandwich panel slabs: Advanced numerical simulations and parametric studies.

Paper submitted to Composite Structures, Elsevier, ISSN 0263-8223. 


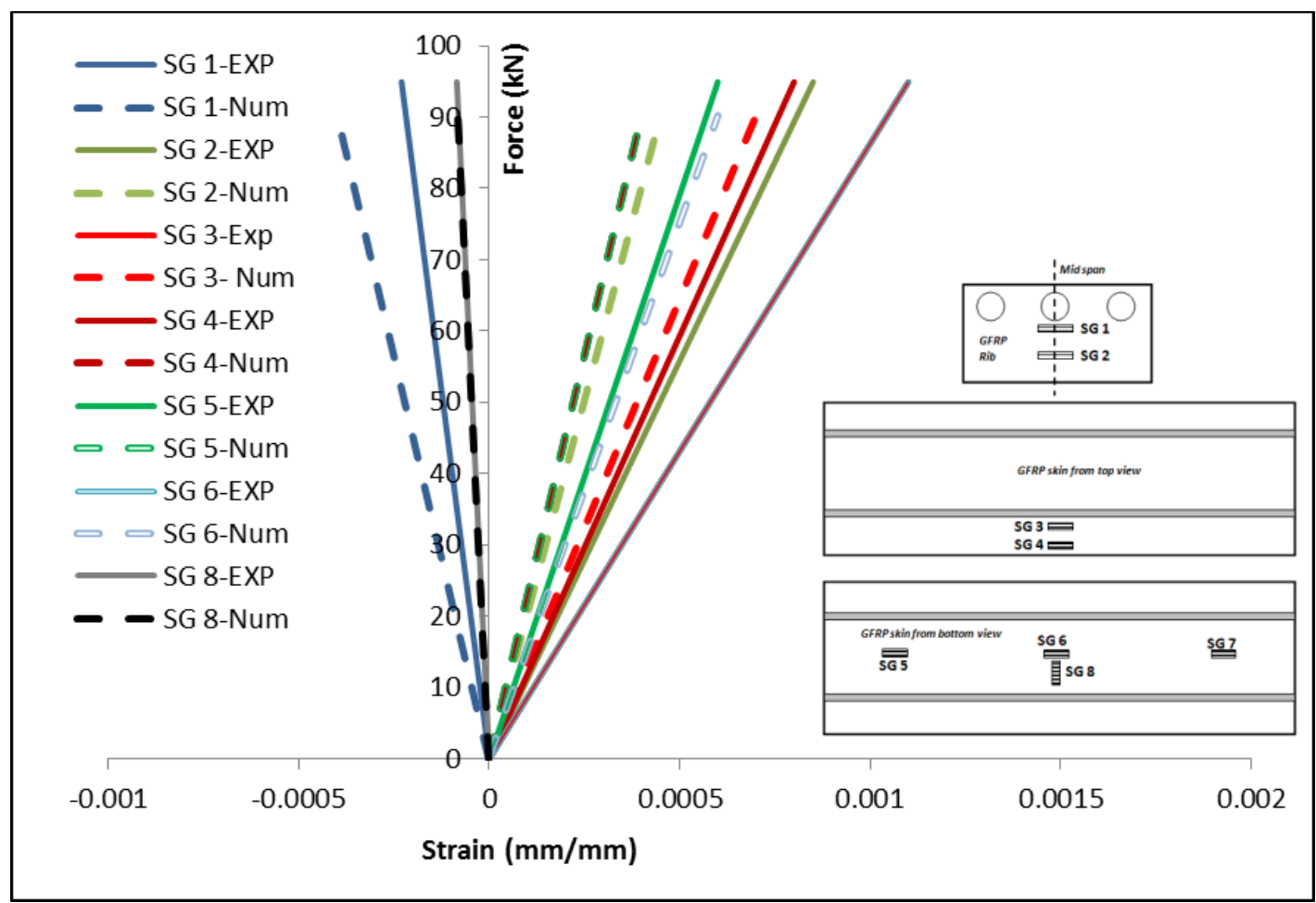

a) Slab 1

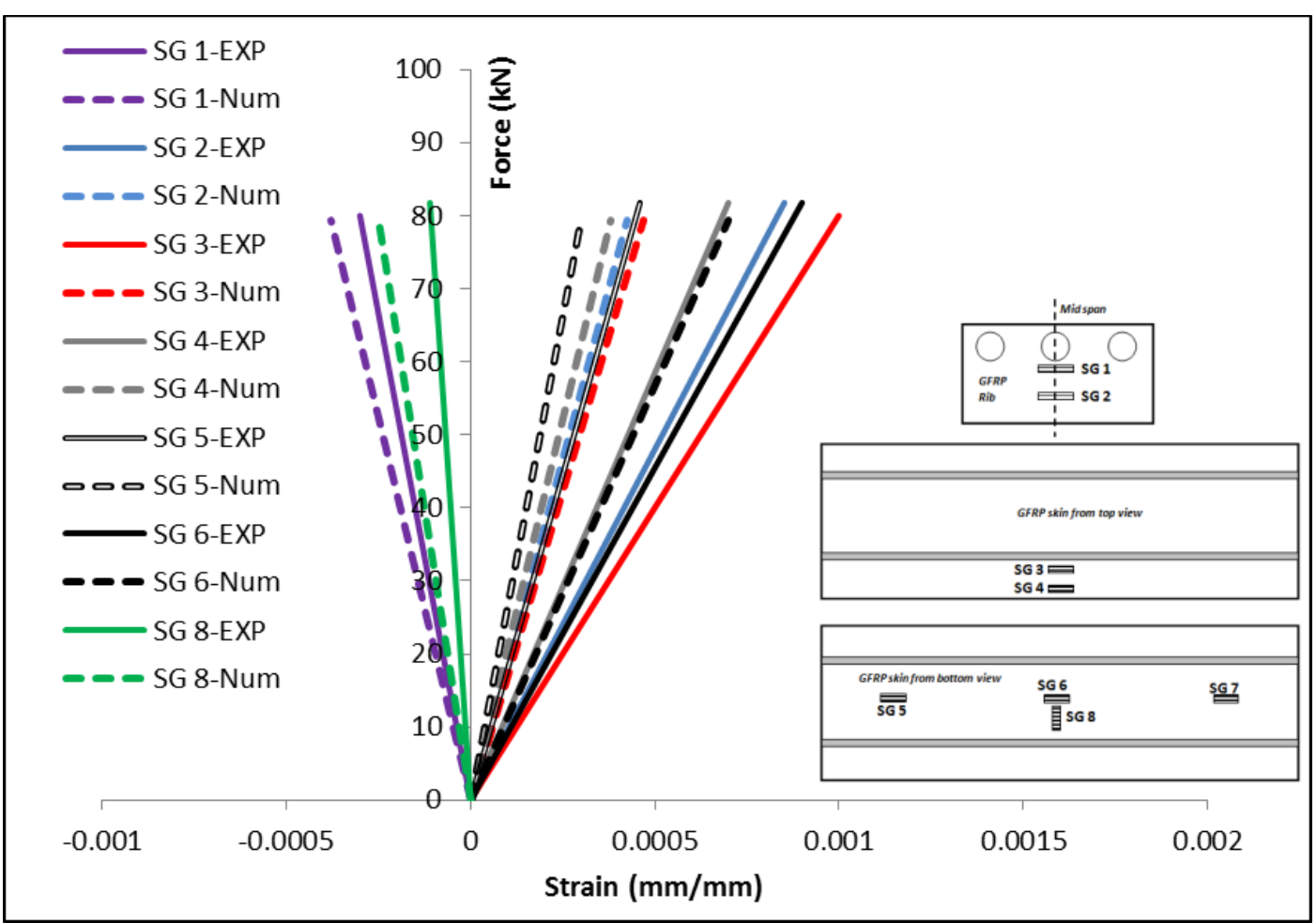

b) Slab 2

Fig 14. Comparison between strain values measured in the experimental tests and obtained in numerical simulations

Mastali, Mohammad, Valente, Isabel B., Barros, Joaquim A. O. (2016).

Development of innovative hybrid sandwich panel slabs: Advanced numerical simulations and parametric studies.

Paper submitted to Composite Structures, Elsevier, ISSN 0263-8223. 


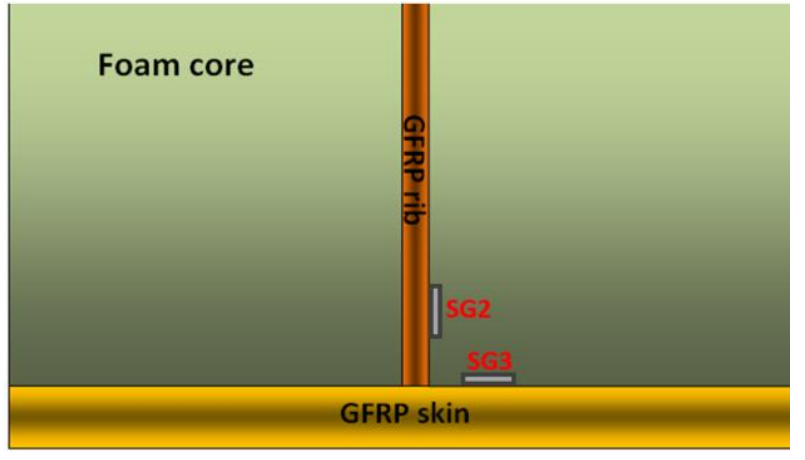

a)

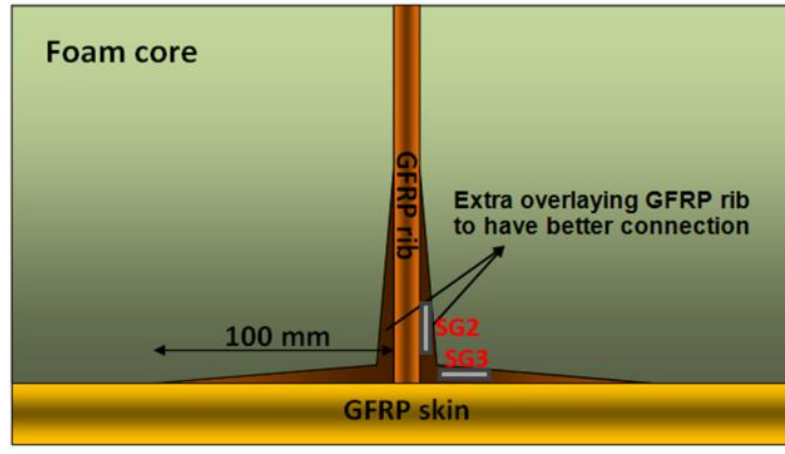

b)

Fig 15. a) Modeled slab's components in the FEM software; b) Thickening of GFRP ribs and GFRP skin in the connection zone [5]

Mastali, Mohammad, Valente, Isabel B., Barros, Joaquim A. O. (2016).

Development of innovative hybrid sandwich panel slabs: Advanced numerical simulations and parametric studies.

Paper submitted to Composite Structures, Elsevier, ISSN 0263-8223. 
Table 1. Properties adopted to simulate the nonlinear behavior of DHCC

\begin{tabular}{l|l}
\hline \multicolumn{2}{c}{ Parameters of $\mathrm{DHCC}$} \\
\hline Poisson's ratio & $v_{c}=0.15$ \\
\hline Initial Young's modulus [5] & $E_{c}=18420 \mathrm{MPa}$ \\
\hline Compressive strength [5] & $f_{c}=24 \mathrm{MPa}$ \\
\hline Maximum number of cracks per integration point & 2 \\
\hline Tri-linear softening diagram parameters [15] & $f_{c t}=2.57 \mathrm{MPa} ; G_{f}^{I}=4.18 \mathrm{~N} / \mathrm{mm}$ \\
\hline $\begin{array}{l}\xi_{1}=0.24 ; \alpha_{1}=1.43 ; \xi_{2}=0.6 ; \alpha_{2}=0.58 \\
\text { available to the new crack [10] }\end{array}$ & 2 \\
\hline Parameter defining the shear retention evolution $\left(p_{1}\right)$ & 2 \\
\hline Crack band-width, $I_{c r}$ & $\begin{array}{l}\text { Square root of the area of the integration } \\
\text { point }(\sqrt{ } \text { Ai) }\end{array}$ \\
\hline
\end{tabular}

The adopted values for the CDP model parameters

\begin{tabular}{l|l}
\hline Dilation angle $(\psi)$ & $38^{0}$ \\
\hline Plastic potential eccentricity $\quad(e)[30]$ & 0.1 \\
\hline Stress ratio ( $\left.f_{b 0} / f_{C 0}\right)[6]$ & 1.16 \\
\hline Shape of the loading surface (Kc) & $2 / 3$ \\
\hline Viscosity parameter (VP) & 0 \\
\hline
\end{tabular}

Mastali, Mohammad, Valente, Isabel B., Barros, Joaquim A. O. (2016).

Development of innovative hybrid sandwich panel slabs: Advanced numerical simulations and parametric studies

Paper submitted to Composite Structures, Elsevier, ISSN 0263-8223. 
Table 2. Mechanical properties used for modeling GFRP ribs and skin (fibers oriented at local axes) [5]

\begin{tabular}{|c|c|c|c|c|c|}
\hline & \multicolumn{2}{|c|}{$\begin{array}{l}\text { Coupon } \\
\text { specimens }\end{array}$} & \multirow{2}{*}{$\begin{array}{l}\text { Tensile strength } \\
\begin{array}{c}\text { [MPa] } \\
170.80\end{array}\end{array}$} & \multirow{2}{*}{$\begin{array}{c}\begin{array}{c}\text { Modulus of } \\
\text { elasticity } \\
\text { [GPa] }\end{array} \\
13.18\end{array}$} & \multirow{2}{*}{$\begin{array}{c}\text { Ultimate strain } \\
\begin{array}{c}\text { [\%] } \\
2.59\end{array}\end{array}$} \\
\hline \multirow{5}{*}{ Slab 1} & \multirow{3}{*}{ Rib } & $0^{\circ}$ & & & \\
\hline & & $90^{\circ}$ & 98.35 & 13.01 & 11.7 \\
\hline & & $45^{\circ}$ & 332.21 & 15.96 & 2.20 \\
\hline & \multirow{2}{*}{ Skin } & $90^{\circ}$ & 65.98 & 13.30 & 2.22 \\
\hline & & $0^{\circ}$ & 785.68 & 31.41 & 2.50 \\
\hline \multirow{5}{*}{ Slab 2} & \multirow{3}{*}{ Rib } & $0^{\circ}$ & 112.50 & 13.03 & 2.40 \\
\hline & & $90^{\circ}$ & 61.08 & 8.62 & 1.51 \\
\hline & & $45^{\circ}$ & 174.00 & 13.63 & 2.35 \\
\hline & \multirow{2}{*}{ Skin } & $90^{\circ}$ & 63.03 & 12.10 & 2.40 \\
\hline & & 0 & 573.00 & 36.06 & 1.66 \\
\hline
\end{tabular}

Mastali, Mohammad, Valente, Isabel B., Barros, Joaquim A. O. (2016).

Development of innovative hybrid sandwich panel slabs: Advanced numerical simulations and parametric studies

Paper submitted to Composite Structures, Elsevier, ISSN 0263-8223. 
Table 3. Properties considered for GFRP materials [11]

\begin{tabular}{|c|c|c|c|c|c|c|c|c|}
\hline $\begin{array}{c}\text { GFRP } \\
\text { material }\end{array}$ & $\begin{array}{c}E_{1} \\
{[\mathrm{GPa}]}\end{array}$ & $\begin{array}{c}E_{2} \\
{[\mathrm{GPa}]}\end{array}$ & $v_{12}$ & $\begin{array}{c}\text { In-plane } \\
\text { shear } \\
\text { modulus } \\
{[\mathrm{GPa}]}\end{array}$ & $\begin{array}{c}\text { Tensile } \\
\text { strength at } \\
0^{0}(1) \\
{[\mathrm{MPa}]}\end{array}$ & $\begin{array}{c}\text { Tensile } \\
\text { strength at } \\
90^{\circ}(2) \\
{[\mathrm{MPa}]}\end{array}$ & $\begin{array}{c}\text { In-plane } \\
\text { shear } \\
\text { strength } \\
{[\mathrm{MPa}]}\end{array}$ & $\begin{array}{c}\text { Compressive } \\
\text { strength at } \\
\pm 45^{\circ}(1) \&(2) \\
{[\mathrm{MPa}]}\end{array}$ \\
\hline Ribs & 12.2 & 12.2 & 0.53 & 8 & ----- & - ---- & 100 & 90 \\
\hline Skin & 40.0 & 8.0 & 0.25 & 4 & 1000 & 30 & ----- & ----- \\
\hline
\end{tabular}

Mastali, Mohammad, Valente, Isabel B., Barros, Joaquim A. O. (2016).

Development of innovative hybrid sandwich panel slabs: Advanced numerical simulations and parametric studies

Paper submitted to Composite Structures, Elsevier, ISSN 0263-8223. 
Table 4. Variables and corresponding values assumed in the parametric study

\begin{tabular}{|c|c|c|c|c|c|c|c|c|c|c|c|c|c|c|}
\hline \multirow{3}{*}{ Name } & \multirow{3}{*}{$\frac{\boldsymbol{H}}{[\mathrm{mm}]}$} & \multicolumn{3}{|c|}{ Thickness } & \multirow{3}{*}{ Name } & \multirow{3}{*}{$\frac{\boldsymbol{H}}{[\mathrm{mm}]}$} & \multicolumn{3}{|c|}{ Thickness } & \multirow{3}{*}{ Name } & \multirow{3}{*}{$\frac{\boldsymbol{H}}{[\mathrm{mm}]}$} & \multicolumn{3}{|c|}{ Thickness } \\
\hline & & $B$ & $C$ & $D$ & & & $B$ & $C$ & $D$ & & & $B$ & $C$ & $D$ \\
\hline & & \multicolumn{3}{|c|}{$[\mathrm{mm}]$} & & & & {$[\mathrm{mm}]$} & & & & \multicolumn{3}{|c|}{$[\mathrm{mm}]$} \\
\hline SGH 1 & \multirow{11}{*}{162.5} & 10 & 2 & 5 & SMH 1 & \multirow{11}{*}{130} & 10 & 2 & 5 & SZH 1 & \multirow{11}{*}{100} & 10 & 2 & 5 \\
\hline SGH 2 & & 15 & 2 & 5 & $\mathrm{SMH} 2$ & & 15 & 2 & 5 & $\mathrm{SZH} 2$ & & 15 & 2 & 5 \\
\hline SGH 3 & & 20 & 2 & 5 & $\mathrm{SMH} 3$ & & 20 & 2 & 5 & SZH 3 & & 20 & 2 & 5 \\
\hline SGH 4 & & 25 & 2 & 5 & SMH 4 & & 25 & 2 & 5 & SZH 4 & & 25 & 2 & 5 \\
\hline SGH 5 & & 30 & 2 & 5 & SMH 5 & & 30 & 2 & 5 & SZH 5 & & 30 & 2 & 5 \\
\hline SGR 2 & & 30 & 4 & 5 & SMR 2 & & 30 & 4 & 5 & SZR 2 & & 30 & 4 & 5 \\
\hline SGR 3 & & 30 & 6 & 5 & SMR 3 & & 30 & 6 & 5 & SZR 3 & & 30 & 6 & 5 \\
\hline SGR 4 & & 30 & 8 & 5 & SMR 4 & & 30 & 8 & 5 & SZR 4 & & 30 & 8 & 5 \\
\hline SGR 5 & & 30 & 10 & 5 & SMR 5 & & 30 & 10 & 5 & SZR 5 & & 30 & 10 & 5 \\
\hline SGS 1 & & 30 & 2 & 2 & SMS 1 & & 30 & 2 & 2 & SZS 1 & & 30 & 2 & 2 \\
\hline SGS 3 & & 30 & 2 & 8 & SMS 3 & & 30 & 2 & 8 & SZS 3 & & 30 & 2 & 8 \\
\hline
\end{tabular}

Mastali, Mohammad, Valente, Isabel B., Barros, Joaquim A. O. (2016).

Development of innovative hybrid sandwich panel slabs: Advanced numerical simulations and parametric studies

Paper submitted to Composite Structures, Elsevier, ISSN 0263-8223. 
Table 5. The proposed optimized slabs and the corresponding results

\begin{tabular}{|c|c|c|c|c|c|c|c|c|c|c|c|c|}
\hline Name & $H$ & $\begin{array}{c}B \\
{[\mathrm{~mm}]}\end{array}$ & $C$ & $D$ & $\begin{array}{c}\text { Maximum } \\
\text { crack } \\
\text { width } \\
{[\mathrm{mm}]}\end{array}$ & $\begin{array}{l}\text { Force } \\
{[\mathrm{kN}]}\end{array}$ & $\begin{array}{c}\sigma_{\text {GFRP }} 90 \\
{[\mathrm{MPa}]}\end{array}$ & $\begin{array}{c}\sigma_{\text {GFRP } 0} \\
{[\mathrm{MPa}]}\end{array}$ & $\begin{array}{c}\tau_{G F R P} \\
{[\mathrm{MPa}]}\end{array}$ & $\begin{array}{l}\sigma_{\mathrm{DHCC}} \\
{[\mathrm{MPa}]}\end{array}$ & $\begin{array}{c}\text { Deflection } \\
\text { [mm] }\end{array}$ & $\alpha$ \\
\hline SGO 1 & & 30 & 6 & 5 & 0.0023 & 249.46 & 13.74 & 44.50 & 24.12 & 8.65 & 3.24 & 9.35 \\
\hline SGO 2 & 162.5 & 30 & 6 & 3 & ----- & 181.34 & 11.06 & 46.88 & 17.67 & 6.98 & 4.27 & 6.54 \\
\hline SGO 3 & & 20 & 6 & 3 & 0.0036 & 165.65 & 10.90 & 44.20 & 16.20 & 7.87 & 4.66 & 5.88 \\
\hline SMO 1 & & 20 & 4 & 5 & 0.0038 & 149.05 & 10.71 & 35.15 & 15.73 & 8.50 & 4.87 & 5.34 \\
\hline SMO 2 & 12 & 20 & 6 & 3 & ----- & 103.69 & 8.46 & 35.56 & 11.12 & 6.37 & 6.44 & 3.46 \\
\hline SMO 3 & 130.0 & 30 & 6 & 2 & ----- & 167.23 & 11.50 & 37.74 & 17.61 & 7.55 & 4.74 & 7.38 \\
\hline SMO 4 & & 30 & 6 & 3 & ----- & 22.13 & 9.49 & 40.38 & 13.30 & 6.18 & 6.13 & 4.13 \\
\hline
\end{tabular}

$\sigma_{\text {GFRP } 90}$ and $\sigma_{\text {GFRP } 0}$ are measured in the GFRP bottom skin. 
Table 6. Buckling due to in-plane shear and compressive stress in optimized specimens

\begin{tabular}{|c|c|c|c|c|c|c|}
\hline Name & $\begin{array}{c}\text { Critical buckling } \\
\text { stress due to in- } \\
\text { plane shear in ribs } \\
{[\mathrm{MPa}]}\end{array}$ & $\begin{array}{c}\tau_{\text {in-plane }} \\
\text { [MPa] }\end{array}$ & $\begin{array}{c}\text { Critical buckling } \\
\text { stress due } \\
\text { compression in } \\
\text { ribs } \\
{[\mathrm{MPa}]}\end{array}$ & $\begin{array}{c}\sigma_{\text {compressive }} \\
{[\mathrm{MPa}]}\end{array}$ & Status & $\begin{array}{c}\text { Price } \\
{\left[\text { Euro } / \mathrm{m}^{2}\right]}\end{array}$ \\
\hline SGO 1 & 32.10 & 24.12 & 181.78 & 16.20 & Ok & 180 \\
\hline SGO 2 & 32.10 & 17.67 & 181.78 & 38.38 & Ok & 170 \\
\hline SGO 3 & 32.10 & 16.20 & 181.78 & 35.11 & Ok & 150 \\
\hline SMO 1 & 50.16 & 15.73 & 284.04 & 17.67 & Ok & 130 \\
\hline SMO 2 & 50.16 & 11.12 & 284.04 & 22.65 & Ok & 140 \\
\hline SMO 3 & 50.16 & 17.61 & 284.04 & 10.20 & Ok & 145 \\
\hline SMO 4 & 50.16 & 13.30 & 284.04 & 26.64 & Ok & 155 \\
\hline
\end{tabular}

Mastali, Mohammad, Valente, Isabel B., Barros, Joaquim A. O. (2016).

Development of innovative hybrid sandwich panel slabs: Advanced numerical simulations and parametric studies

Paper submitted to Composite Structures, Elsevier, ISSN 0263-8223. 
Table 7. Detailed properties of the tested specimens

\begin{tabular}{c|c|c|c|c}
\hline \multirow{2}{*}{ Name } & \multirow{2}{*}{ Material name } & Material type & \multicolumn{2}{|c}{ Height or Width [mm] } \\
\cline { 3 - 4 } & & & Slab 1 & Slab 2 \\
\hline A & Foam core & Polyurethane & 149 & 115 \\
B & DHCC & Reinforced mortar & 20 & 20 \\
C & GFRP skin & GFRP & 3 & 5 \\
D & Foam core & Polyurethane & 119 & 85 \\
E & GFRP rib & GFRP & 160 & 130 \\
F & DHCC & Reinforced mortar & 50 & 50 \\
G & Foam core & Polyurethane & 260 & 260 \\
H & Foam core & Polyurethane & 400 & 400 \\
I & GFRP rib & GFRP & 6 & 4 \\
K & Foam core & Polyurethane & 200 & 200 \\
L & Foam core & Polyurethane & 130 & 130 \\
M & Foam core & Polyurethane & 40 & 40 \\
\hline
\end{tabular}

Mastali, Mohammad, Valente, Isabel B., Barros, Joaquim A. O. (2016).

Development of innovative hybrid sandwich panel slabs: Advanced numerical simulations and parametric studies

Paper submitted to Composite Structures, Elsevier, ISSN 0263-8223. 
Table 8. Obtained parameters, stresses and fracture energy for the bi-linear tractionseparation law through inverse analysis

\begin{tabular}{|c|c|c|c|c|c|}
\hline & & \multicolumn{2}{|c|}{ Slab 1} & \multicolumn{2}{|c|}{ Slab 2} \\
\hline & & $\begin{array}{l}\text { DHCC layer } \\
\text { to GFRP rib }\end{array}$ & $\begin{array}{l}\text { DHCC layer to } \\
\text { foam core }\end{array}$ & $\begin{array}{l}\text { DHCC layer } \\
\text { to GFRP rib }\end{array}$ & $\begin{array}{l}\text { DHCC layer to } \\
\text { foam core }\end{array}$ \\
\hline$T_{\max }$ & {$\left[\mathrm{N} / \mathrm{mm}^{2}\right]$} & 10.00 & 1.00 & 7.00 & 0.20 \\
\hline$K_{0}$ & {$\left[\mathrm{~N} / \mathrm{mm}^{3}\right]$} & 2500.0 & 200.0 & 1658.0 & 162.0 \\
\hline$G_{G r}$ & {$[\mathrm{~N} / \mathrm{mm}]$} & 5.00 & 0.10 & 4.00 & 0.10 \\
\hline$\delta_{0}$ & {$[\mathrm{~mm}]$} & 0.004 & 0.005 & 0.004 & 0.001 \\
\hline$\delta_{f}$ & {$[\mathrm{~mm}]$} & 1.00 & 0.20 & 1.14 & 1.00 \\
\hline $\begin{array}{c}\text { Normal stress } \\
\left(\sigma_{n}{ }^{9}\right)\end{array}$ & {$\left[\mathrm{N} / \mathrm{mm}^{2}\right]$} & 30.0 & 5.0 & 25.0 & 10.0 \\
\hline $\begin{array}{c}\text { Shear stress in } \\
\text { the } 1^{\text {st }} \text { direction } \\
\left(\tau_{1}^{0}\right)\end{array}$ & {$\left[\mathrm{N} / \mathrm{mm}^{2}\right]$} & 10.0 & 1.0 & 7.0 & 0.2 \\
\hline $\begin{array}{c}\text { Shear stress in } \\
\text { the } 2^{\text {nd }} \text { direction } \\
\left(\tau_{2}\right)^{9}\end{array}$ & {$\left[\mathrm{~N} / \mathrm{mm}^{2}\right]$} & 10.0 & 1.0 & 7.0 & 0.2 \\
\hline $\begin{array}{c}\text { Normal fracture } \\
\text { energy }\end{array}$ & {$[\mathrm{N} / \mathrm{mm}]$} & 10.0 & 0.5 & 9.0 & 1.0 \\
\hline $\begin{array}{l}\text { Fracture energy } \\
\text { for shear in } 1^{\text {st }} \\
\text { direction }\end{array}$ & {$[\mathrm{N} / \mathrm{mm}]$} & 5.0 & 0.1 & 4.0 & 0.1 \\
\hline $\begin{array}{l}\text { Fracture energy } \\
\text { for shear in } 2^{\text {nd }} \\
\text { direction }\end{array}$ & {$[\mathrm{N} / \mathrm{mm}]$} & 5.0 & 0.1 & 4.0 & 0.1 \\
\hline
\end{tabular}

Mastali, Mohammad, Valente, Isabel B., Barros, Joaquim A. O. (2016).

Development of innovative hybrid sandwich panel slabs: Advanced numerical simulations and parametric studies

Paper submitted to Composite Structures, Elsevier, ISSN 0263-8223. 
Table 9. Obtained error percentages due to use perfect bond and cohesive zone model

\begin{tabular}{c|c|c|c|c|c|c}
\cline { 2 - 6 } Bond type & $\begin{array}{c}\text { Error in } \\
\text { force } \\
{[\%]}\end{array}$ & $\begin{array}{c}\text { Error in } \\
\text { deflection } \\
{[\%]}\end{array}$ & $\begin{array}{c}\text { Error in } \\
\text { stiffness } \\
{[\%]}\end{array}$ & $\begin{array}{c}\text { Error in } \\
\text { force } \\
{[\%]}\end{array}$ & $\begin{array}{c}\text { Error in } \\
\text { deflection } \\
{[\%]}\end{array}$ & $\begin{array}{c}\text { Error in } \\
\text { stiffness } \\
{[\%]}\end{array}$ \\
\hline $\begin{array}{c}\text { Cohesive zone } \\
\text { model (CZM) }\end{array}$ & +7.7 & -2.8 & +3.8 & -3.3 & -7.0 & +3.5 \\
\hline Perfect bond & -18.1 & -13.8 & +4.7 & -15.9 & -28.4 & +10.8 \\
\hline
\end{tabular}

Mastali, Mohammad, Valente, Isabel B., Barros, Joaquim A. O. (2016).

Development of innovative hybrid sandwich panel slabs: Advanced numerical simulations and parametric studies

Paper submitted to Composite Structures, Elsevier, ISSN 0263-8223. 